\title{
Mechanisms of Stability of Armored Bubbles: FY 1996 Final Report
}

W. R. Rossen

S. I. Kam

November 1996

Prepared by the Department of Petroleum and Geosystems Engineering The University of Texas at Austin for Pacific Northwest National Laboratory under Contract DE-AC06-76RLO 1830 and Agreement 283947-A-I3, Supplement 1

Pacific Northwest National Laboratory Richland, Washington 99352

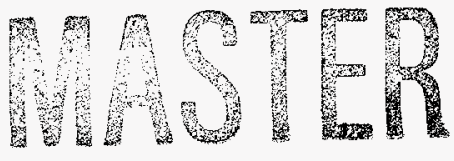





\section{DISCLAMIER}

Portions of this document may be illegible in electronic image produets. Images are produced from the best available original document. 


\section{SUMMARY}

Theoretical and experimental studies examine how a coating, or "armor," of partially wetted solid particles can stabilize tiny bubbles against diffusion of gas into the surrounding liquid, in spite of the high capillary pressures normally associated with such bubbles. Experiments with polymethylmethacrylate (PMMA) beads and carbonated water demonstrate that armored bubbles can persist for weeks in liquid unsaturated with respect to the gas in the bubbles. A two-dimensional model for armored bubbles shows how an armor can support a liquid-vapor interface of reduced or reversed curvature between the particles, giving the bubble zero or even negative capillary pressure. The stresses on the solid-solid contacts between particles in such cases is large and could drive sintering of the particles into a rigid framework.

Stability analysis suggests that a slightly shrunken bubble would not expel a solid particle from its armor to relieve stress and allow the bubble to shrink further. Expulsion of particles from more stressed bubbles a zero capillary pressure is energetically favored in some cases. It is not clear, however, whether this expulsion would proceed spontaneously from a small perturbation or require a large initial disturbance of the bubble. In some cases, it appears that a bubble would expel some particles and shrink, but the bubble would approach a final, stable size rather than disappear completely.

This simplified analysis leaves out several factors. For instance, only one perturbation toward expelling a solid from the armor is considered; perhaps other perturbations would be more energetically favored than that tested. Other considerations (particle deformation, surface roughness, contact-angle hysteresis, and adhesion or physical bonding between adjacent particles) would make expelling solids more difficult than indicated by this theoretical study. 



\section{TABLE OF CONTENTS}

Summary . . . . . . . . . . . iii

Introduction . . . . . . . . . . 1

Objectives . . . . . . . . . . . 3

Experiments . . . . . . . . . . 3

Approach . . . . . . . . . . 3

Results and Discussion . . . . . . 4

Theory . . . . . . . . . 5

Approach . . . . . . . . . . 5

Results and Discussion . . . . . 9

Armor at Rest . . . . . . . 9

Armor Under Stress . . • • • 10

Stability of Armor Under Stress . $\quad . \quad 13$

Conclusions . . . . . . . . . . 16

Symbols . . . . . . . . . . . . 17

References . . . . . . . . 18

Appendix . . . . . . . . . . . 21

Tables . . . . . . . . . . 23

Figures . . . . . . . . . . . . 25 


\section{INTRODUCTION}

Concern about gas discharges from waste tanks at the Hanford nuclear reservation has led to the study of the mechanisms by which gas is trapped in and then episodically released from these tanks. ${ }^{1-5}$ One possible mechanism by which gas could be held within the tanks is bubbles that are coated with solid particles, or "armored"; the higher density of the solids could keep such a bubble suspended in the midst of the liquid rather than rising to the upper surface of the liquid and bursting. (The coating of solids might also prevent rupture of the bubble at the upper surface of the tank, allowing the armored bubble to become part of the floating crust atop the waste, ${ }^{1-4}$ but prevention of bubble rupture ${ }^{5}$ is outside the scope of this study.)

Tiny bubbles are in general unstable in the midst of a liquid phase for two reasons. First, their lower density causes them to rise through the liquid. An armor of dense solids could prevent this, but this matching of armored bubble density with surrounding liquid is unstable. If the bubble is perturbed upward through the liquid, it expands due to decreasing hydrostatic pressure, further decreasing bubble density and accelerating its rise; and vice versa if the bubble is perturbed downward. Bubbles thus perturbed might stop their rise at the bottom of the crust atop the waste, or stop their fall at the top of the sludge layer below the liquid.

The second instability concerns mass transfer with the surrounding liquid. The higher gas pressure in the bubble, due to surface tension, the curved bubble surface and the resulting capillary pressure $p_{c}$ is given by

$$
p_{c} \equiv p_{v}-p_{l}=\frac{2 \gamma l v}{R_{l v}}
$$

where $p_{v}$ is the pressure in the gas bubble, $p_{1}$ is the pressure in the liquid, $\gamma_{1 v}$ is the surface tension between liquid and vapor, and $R_{1 v}$ is the radius of curvature of the liquid-vapor interface, which is defined as positive if the surface is convex around the center of the bubble. For a bubble that is not coated with solids, $R_{1 v}$ is simply the radius of the spherical bubble. The increase in gas pressure in 
the bubble indicated by Eq. 1 raises gas chemical potential, which drives gas redissolution into the liquid. ${ }^{7}$

The process of gas redissolution is complicated in the Hanford tanks by chemical generation of the gaseous chemical component in the liquid phase; as a result, the liquid is likely to be supersaturated with gas. If the liquid were only slightly supersaturated, the smallest bubbles would still lose material to larger bubbles in the vicinity. More specifically, for any finite degree of supersaturation, bubbles smaller than some threshold size would disappear, while larger bubbles would grow without limit. Stability of small bubbles to mass transfer requires a mechanism whereby, as a bubble shrinks, its capillary pressure falls, shutting down gas redissolution, rather than $\mathrm{p}_{\mathrm{c}}$ rising as the bubble shrinks, as indicated by Eq. 1.

Solid particles that are not perfectly wetted by either gas or liquid accumulate at the surface of a bubble because overall energy is minimized with these solids placed along the interface between liquid and vapor. ${ }^{6}$ This is the basis, for instance, of froth flotation of minerals in the mining industry. ${ }^{8}$ An armor of partially-wetted solid particles around a bubble can in turn form a framework that might support such the bubble against shrinkage due to gas dissolution. If this armor remains intact as the bubble shrinks slightly, then reduced, zero or even negative interfacial curvatures can be supported, though the overall shape of the armor would remain spherical. Examples are shown in this report. Once the curvature is reduced or reversed, then the driving force for gas redissolution into liquid is eliminated. Supporting the liquid-gas interface in such cases puts large stresses on the armor. It is plausible that the bubble might expel a particle from the armor to relieve this stress and allow the bubble to shrink further. One purpose of this report is to investigate under what conditions such an armor can support this stress, and whether the stressed state is stable, or the bubble would continue shrinking, expelling solids from its armór as needed to shrink further. 


\section{OBJECTIVES}

The specific objectives of this study are as follows:

- Demonstrate experimentally, using a simple physical model, that bubbles can be stabilized for long times in unsaturated liquid by solids coating the surfaces of the bubbles.

- Derive theoretically the conditions under which solids can stabilize bubbles against gas dissolution into liquid by supporting a liquid-vapor interface with zero or negative curvature. Specifically,

- derive the conditions of static equilibrium for such a bubble, and

- determine under what conditions such a slightly shrunken bubble would expel a solid particle from its coating in order to allow itself to shrink further.

\section{EXPERIMENTS}

\section{Approach}

We sought a system in which gas solubility in liquid can be manipulated easily in the laboratory. The solubility of $\mathrm{CO}_{2}$ in water is sensitive to both pressure and temperature ${ }^{9}$ (Figure 1), and water with large amounts of $\mathrm{CO}_{2}$ dissolved under pressure can be purchased at nearly any grocery store. Polymethylmethacrylate (PMMA) beads are partially wetted by water and have been shown to stabilize froths on water. ${ }^{4}$ Ozarka ${ }^{\mathrm{TM}}$ brand mineral water (plain) was used as the liquid phase in these experiments. PMMA beads (Elvacite ${ }^{\circledR}$ Acrylic resins, with mean particle diameter about $100 \mu \mathrm{m} ; 15 \%$ smaller than $90 \mu \mathrm{m}, 15 \%$ larger than $130 \mu \mathrm{m}$ ) were obtained from ICI Acrylics, Wilmington, DE. A sample of a flat sheet of PMMA (Lucite ${ }^{\circledR} \mathrm{L}$, cast acrylic) of the same composition as the beads were obtained from Regal Plastics. The contact angle of deionized water on the sheet, determined using a goniometer, was $70^{\circ}$. This intermediate wettability is ideal for particle adhesion to the liquid-vapor interface. ${ }^{6}$

In our first experiment, PMMA particles were carefully added to a small amount of 
water in a beaker so as not to trap air in the beads or accumulate beads at the interface. Some beads did remain at the liquid-vapor interface, and these were scooped out or detached and sank upon addition of more water. The beaker was then heated to boiling on a hotplate. A froth was formed, containing water vapor and perhaps gases dissolved in the water. Some of these bubbles remained stable at the top of the liquid for over a day. The exact vapor composition of the bubbles is not known.

Our second set of experiments attempted to create bubbles of $\mathrm{CO}_{2}$ in water, stabilized by PMMA particles, under conditions where $\mathrm{CO}_{2}$ would normally redissolve back into the water. We carefully added PMMA particles and then cold, carbonated water to a chilled beaker so that no armored bubbles were present initially. We then allowed the carbonated water to warm to room temperature slowly, or, sometimes, more quickly, on a hotplate. A solids-stabilized froth was formed, as in earlier studies at PNL and in this laboratory, in which nitrogen was sparged through water with PMMA beads or simulated tank wastes. ${ }^{1-5}$ The vapor space above the solution was loosely sealed, so that $\mathrm{CO}_{2}$ evolving from the liquid would drive out air and fill the vapor space above the liquid. Thus, it is hoped, the dissolved $\mathrm{CO}_{2}$ and $\mathrm{CO}_{2}$ bubbles were at equilibrium with a vapor of pure $\mathrm{CO}_{2}$ at $1 \mathrm{~atm}$ pressure shortly after the start of the experiment. We then heated the solution above room temperature on the hotplate and allowed the solution to cool slowly back to room temperature. Under these conditions, since $\mathrm{CO}_{2}$ solubility decreases with increasing temperature (Figure 1), $\mathrm{CO}_{2}$ bubbles created in the warm water should redissolve back into the liquid upon cooling. The initial pressurized carbonation of the mineral water helps to form a froth, but it is increase in $\mathrm{CO}_{2}$ solubility in water as the liquid cools back to room temperature at $1 \mathrm{~atm}$ pressure that is at the heart of the demonstration.

\section{Results and Discussion}

After cooling the carbonated liquid back to room temperature, a portion of froth persisted for several weeks, indicating that the solids stabilized the bubbles against the 
redissolution of $\mathrm{CO}_{2}$ into water, now unsaturated with respect to $\mathrm{CO}_{2}$.

Similar results were obtained in a previous study of nitrogen sparging of synthetic Hanford waste. 5 In that case, tiny bubbles of $\mathrm{N}_{2}$ were stabilized for weeks against diffusion through the liquid film surrounding the bubble into the surrounding air. Large bubbles (of size $1 \mathrm{~mm}$ or larger) disappeared relatively rapidly in that test. In this new test, however, when the carbonated water was brought to boiling, most of the long-lived bubbles formed were of order $1 \mathrm{~mm}$ or larger in size. When the carbonated water warmed slowly to room temperature only, the long-lived bubbles were much smaller. In all cases, only a small fraction of the gas evolved from the liquid was trapped in long-lived bubbles.

This new demonstration was intended to show stabilization of bubbles against gas redissolution into unsaturated liquid. Unfortunately, the exact composition of the liquid and vapor surrounding the armored bubbles is not clear in this test. At the elevated temperature, if $\mathrm{CO}_{2}$ were slow to evolve, then the liquid might not have been unsaturated upon cooling. On the other hand, some air undoubtedly re-entered the vapor space above the liquid as the beaker cooled. As the cooled liquid came into equilibrium with this mixed vapor, its concentration of dissolved $\mathrm{CO}_{2}$ probably fell below that intended: i.e., in equilibrium with $\mathrm{CO}_{2}$ at $1 \mathrm{~atm}$ pressure. In any event, as in previous tests, ${ }^{4,5}$ the solids clearly stabilized small bubbles against mass transfer to liquid and vapor, in apparent violation of the implications of Eq. 1.

\section{THEORY}

\section{Approach}

Armored bubbles are coated with irregular-shaped solid particles that may or may not adhere to each other. For simplicity, one might idealize these particles as inert, uniform and spherical. Two properties of such an idealized system are worth noting: (1) Until the particles are close-packed, there is no distortion of the spherical shape of the liquid-vapor interface around the solid particles. ${ }^{10}$ The spherical symmetry of the particles meshes 
smoothly with the spherical symmetry of the bubble. The familiar everyday observation that bubbles clump together on a flat liquid-vapor interface, in a beverage glass, for instance, is due to the curved meniscus of the interface around the bubbles due to gravity. 6 In contrast, gravity is not important compared to surface forces on the length scale of the interface of tiny bubbles in the midst of liquid. Similarly, the clumping of solid particles together in a flat armored liquid film between two bubbles 5 is due to the curved interface between the solids in such a film. There is no such distortion in the case of spherical solids around a single spherical bubble. For irregular-shaped solids, there could be some local distortions of the interface, however. (2) Even when particles are close-packed, there are gaps, with exposed liquid-gas interface, between particles - for instance, the gap between three spherical particles shown in Figure $2 \mathrm{a}$.

Although the interface shape is simple and spherical up to the point of close packing of the particles, once the bubble shrinks further the interface shape becomes complex. Therefore we further simplify the problem by considering a two-dimensional (2D) system illustrated in Figures $2 \mathrm{~b}$ and 3. All interface shapes are assumed invariant in the $\mathrm{z}$ direction, perpendicular to this figure. For cylindrical interfaces, capillary pressure is given by

$$
\mathrm{p}_{\mathrm{c}}=\frac{\gamma_{\mathrm{lv}}}{\mathrm{R}_{\mathrm{lv}}}
$$

For simplicity, we assume that gas, liquid and solids are incompressible. We assume that there is no adhesion, sticking or bonding between the solid particles.

In a $2 \mathrm{D}$ system of close-packed solids, there is no gap between solids like that where three spherical solids meet in 3D (Figure 2a). In 2D, in particular, for contact angles other than $90^{\circ}$, there is a potential singularity in interfacial curvature as the liquid-gas interface approaches the point of contact between the solids. Therefore, to eliminate this 
singularity and more accurately model 3D behavior, we postulate that the centers of uniform particles of radius $R_{p}$ can approach no closer than $\left(R_{p}+\delta\right)$ (Figure $\left.2 b\right)$. At this distance hard-sphere repulsion keeps the particles apart, even though there is a small gap and exposed liquid-vapor interface between the particles. For a perfect hexagonal packing of spherical solids on a flat surface (Figure $2 \mathrm{a}$ ), the solids cover $90.69 \%$ of the surface. For the 2D system illustrated in Figure $2 b$, the same fraction of exposed surface corresponds to $\delta=0.05008 \mathrm{R}_{\mathrm{p}}$.

We consider four cases:

1) A loose armor of solids partially covers the bubble.

2) A close-fitting armor of particles covers the bubble, with no stress on the armor (Figure 3).

3) After further bubble shrinkage, the armor supports reduced or reversed curvature of liquid-vapor interface, but the armor retains its initial circular shape (Figure 4a).

4) A single particle is expelled from the armor far enough that the liquid-vapor interface everywhere else can return to a circular shape centered on the center of the bubble (Figure $4 \mathrm{~b}$ ).

For the first three cases we compute the forces acting on the solid particles, including the stress on the solids. For the third and fourth case we compute the appropriate energy change to evaluate whether the system would spontaneously expel a particle in order to relax its interface shape. Levine and Bowen ${ }^{10,11}$ derive effective interfacial properties for an armored bubble on the assumption that the armor sustains no stress, i.e. that it expels particles continuously as the bubble shrinks, but we know of no theoretical demonstration that a system would spontaneously do so.

The computation of energy change is similar to that for a bubble with no solids. ${ }^{7}$ The bubble and surrounding liquid are in a closed container held at fixed temperature $T$ and pressure $\mathrm{p}$ (Figure 5). This subsystem forms part of a larger, closed, adiabatic, constant- 
volume system that includes the temperature and pressure reservoirs. The change in energy in the entire system between cases (3) and (4) above is then

$$
\Delta \mathrm{U}=\mathrm{p}_{\mathrm{c}} \mathrm{dV} \mathrm{v}+\gamma_{\mathrm{sv}} \Delta \mathrm{A}_{\mathrm{SV}}+\gamma_{\mathrm{sl}} \Delta \mathrm{A}_{\mathrm{Sl}}+\gamma_{\mathrm{lv}} \Delta \mathrm{A}_{\mathrm{lv}}
$$

where $A_{i j}$ and $\gamma_{i j}$ are surface areas and excess energies between phases $i$ and $j$, and subscripts $\mathrm{s}, 1$, and $\mathrm{v}$ refer to solid, liquid and vapor phases. If the phases are incompressible, the first term on the right in Eq. 3 is zero. Since, from Young's equation,

$$
\gamma_{\mathrm{s} 1}+\gamma_{\mathrm{v}} \cos \theta=\gamma_{\mathrm{sv}}
$$

where $\theta$ is contact angle, and

$$
\Delta \mathrm{A}_{\mathrm{Sv}}=-\Delta \mathrm{A}_{\mathbf{s}}
$$

then Eq. 3 can be rewritten

$$
\Delta \mathrm{U}=\gamma_{\mathrm{v}}\left(\Delta \mathrm{A}_{\mathrm{lv}}+\Delta \mathrm{A}_{\mathrm{Sv}} \cos \theta\right)
$$

Computation of the positions of the particles and interfaces, forces, and energy change is in concept simple but complex algebraically. Details are given in the Appendix. Briefly, there are three forces acting on the a solid particle, illustrated in Figure 6, where coordinate $y$ is in the direction of the center of the bubble. First, the liquid-vapor interface pulls on the solid at the three-phase contact point in the direction of the tangent to the liquidvapor interface. Second, the lower pressure in the liquid phase gives a net force normal to the surface over the area exposed to the liquid phase. In both cases, the $x$ components of these forces cancel due to symmetry; the net force $F_{y c}$ in the $y$ direction from these two sources represents inward force on the solid arising from capillary forces. If $F_{y c}>0$, it is balanced by the $y$ component of the hard-core repulsive force $F_{S}$ of the neighboring solid particles. 


\section{Results and Discussion}

\section{Armor at Rest}

Figure 7 shows the radial force $F_{y c}$ (cf. Figure 6) on a solid particle from, respectively, interfacial tension and capillary pressure, as a function of contact angle $\theta$. The liquid-vapor interface is a circle centered on the center of the gas bubble with radius 10 times particle radius $R_{p}$. All forces are made dimensionless by dividing by $(\gamma L)$, where $L$ is the length of the cylindrical solids perpendicular to the plane of Figure 2 and $\gamma \equiv \eta_{v}$. For simplicity, here and below we drop the subscripts on $\gamma_{1 \mathrm{v}}$. As shown in the figure, the two capillary forces cancel; there is no net inward force on the particle, and no force between solids is required to resist it, even if the solids are touching. If a bubble with a certain number $\mathrm{n}$ of solid particles begins to shrink due to gas dissolution in the liquid, this condition applies up to the point at which the solid particles are close packed. We designate the gas volume at this point $V_{i}$. If the bubble shrinks beyond this point, the liquid-vapor interface between particles, though still a circle, is no longer centered on the center of the bubble; cf. Figure $4 \mathrm{a}$, where each liquid-vapor interface is flat, i.e. a circle of infinite radius.

If solids particles are relatively large compared to the bubble, then the number of solids on the bubble, $\mathrm{n}$, is small. For such a bubble, a significant fraction of the apparent bubble volume is occupied by the solids. Figure 3 illustrates this schematically for $n=6$. Put differently, a bubble of volume $\mathrm{V}_{\mathrm{i}}$ increases its radius as it acquires an armor, because the solids increase the apparent volume and radius of the bubble. We designate the radius of the bubble with no solids added $R_{l_{v o}}$ and this of the liquid-vapor interface of a bubble with a close-packed but unstressed armor as $\mathbf{R}_{\mathrm{lvi}}$. Figure 8 shows the decrease in capillary pressure due to increased apparent volume as a bubble acquires a close-fitting armor of $n$ particles, for $\theta=10^{\circ}, 70^{\circ}$, and $170^{\circ} . R_{1 v d} / R_{\text {lvi }}$ is the ratio of capillary pressure with armor

to that without armor (Eq. 2). For a close-fitting armor of $n$ particles, Figure 9 shows the ratio of particle radius $R_{p}$ to initial bubble radius $R_{l v o}$. As noted, small values of $n$ 
correspond to particles relatively large compared to initial bubble size.

\section{Armor Under Stress}

If the bubble shrinks further, the solid armor remains fixed; the centers of the solid particles remain in a circular array around the center of the bubble. The liquid-vapor interface begins to flatten and the three-phase contact line moves inward along the solid particles (cf. Figures 3 and 4a). If shrinkage continues, the interfaces reverse curvature and become increasingly concave. By convention, in this case we define the radius of the concave circular interface as negative. Shrinkage reaches a limit when (for $\theta \leq 90^{\circ}$ ), the liquid-vapor interfaces on either side of a particle meet on the solid surface, or (for $\theta \geq 90^{\circ}$ ) the two interfaces meet at a point interior to the solid. In either case, this represents the minimum volume possible before the bubble detaches from at least one solid particle.

Figures 10-18 show the changes in capillary pressure and stresses on solid particles as a bubble shrinks within its armor. Examples are shown for $\mathrm{n}=5,10$ and 100 and $\theta=$ $10^{\circ}, 70^{\circ}$, and $170^{\circ}$. Dimensionless volume, capillary pressure and stresses, respectively, are defined by

$$
\begin{aligned}
& V_{D}=\frac{V}{V_{i}} \\
& P_{c D}=\frac{R_{l v o}}{R_{l v}} \\
& F_{y c D}=\frac{F_{y c}}{\gamma L} \\
& F_{S D}=\frac{F_{S}}{\gamma L}
\end{aligned}
$$

$\mathrm{p}_{\mathrm{CD}}$ is the ratio of the capillary pressure of the shrunken, stressed, armored bubble to that of the initial, unshrunken bubble with no solids. Each plot extends from the unstressed, armored state, through zero capillary pressure to the minimum possible bubble volume. 
For $\theta=10^{\circ}$ and $n=5$ or 10 , the liquid interfaces meet and detach from the solid before $\mathrm{p}_{\mathrm{CD}}$ reaches zero.

In all cases, except those noted just above in which a solid is expelled first, a small decrease in bubble volume causes capillary pressure to decrease to zero and then to negative values. At $\mathrm{p}_{\mathrm{CD}}=0$ the bubble is in equilibrium with liquid saturated with the gaseous component at 1 atm pressure. Thus, at negative $\mathrm{p}_{\mathrm{cD}}$, gas in the bubble can be in equilibrium with liquid unsaturated with the gaseous component. Moreover, this equilibrium is stable to mass-transfer: since $\left(\mathrm{dp}_{\mathrm{cD}} / \mathrm{dV}_{\mathrm{D}}\right)>0$, small perturbations in bubble size drive mass transfer to oppose the perturbations. The instability to density fluctuations discussed in the Introduction remains, however. Since $\left(d V_{D} / d p_{c D}\right)>0$, if a bubble is perturbed upwards, it expands due to lower hydrostatic pressure, further reducing its density and accelerating its rise. As it expands, a bubble may accumulate more solids on its surface, but since area increases more slowly than volume with an increase in bubble size, the instability with respect to density remains. On the other hand, as the bubble rises and expands, its capillary pressure falls, which drives mass transfer out of the bubble by diffusion. Thus whether the bubble would continue to rise or fall upon a small perturbation depends in part on the relative rates of bubble movement and mass transfer with surrounding liquid.

For given $\theta$ and $n$, there is a lower limit to the capillary pressure, and hence degree of unsaturation of the liquid with respect to gas, that a bubble can endure. However, since the Hanford wastes are expected to be supersaturated with respect to gas, the region of practical interest is that of positive capillary pressure.

In most cases, capillary pressure passes through a minimum (negative) value as bubble volume decreases. As the interface recedes further and further from the solids, $\mathrm{R}_{\mathrm{lv}}$ starts to increase. The phenomenon is similar to the increase in interface curvature as an interface advances through a pore throat that causes a Haines jump in two-phase flow in porous media. 12 
Figures 10-18 show the inward radial force on the solid particles $\mathrm{F}_{\mathrm{ycD}}$, derived from interfacial tension and capillary pressure, and $\mathrm{F}_{\mathrm{SD}}$, the solid-solid force, i.e., the stress on the armor, required to keep the solids in place in spite of the capillary forces, for the same values of $\mathbf{n}$ and $\theta$. Because the solids touch at an angle oblique to the radial direction (Figure 6), the solid-solid force is much larger than the radial component of the capillary forces:

$$
F_{s}=\frac{F_{y c}}{2 \sin \left(\frac{\pi}{n}\right)}
$$

For large $\mathrm{n}$ and large decreases in $\mathrm{p}_{\mathrm{c}}$, the stresses on the armor are huge. In all cases, for $\mathrm{p}_{\mathrm{CD}}=0, \mathrm{~F}_{\mathrm{SD}}=1$. In this case there is no force on the solid from the (zero) capillary pressure (Figure 6); surface tension pulls on the particle along the liquid-vapor interface, which by symmetry is a straight line parallel to the line joining the centers of the particles, i.e., the line along which $F_{S}$ acts. Thus $F_{S} \equiv F_{S D} \gamma L=\gamma L$, regardless of $\theta$ or $n$. As $n$ increases, the angle of contact between solids is more oblique to the inward $(y)$ direction (Figure 6), so $F_{y c D}$ decreases, but $F_{S D}$ (Eq. 11) remains unchanged.

In all cases, for $\mathrm{P}_{\mathrm{c}}$ greater than zero or not too negative, Figures $10-18$ indicate that

$$
F_{S D} \cong 1-\left(\frac{p_{C D}}{p_{C D}\left(F_{S D}=0\right)}\right) \cong 1-p_{C D}
$$

Thus one can estimate the stress on the solids for any positive capillary pressure. The denominator in Eq. 12 is nearly 1 for all $\mathrm{n}$ greater than about 5 ; the error in assuming it is 1 is only about $20 \%$ even for $\mathrm{n}=5$. For zero $\mathrm{p}_{\mathrm{c}}$, as noted above, $\mathrm{F}_{\mathrm{S}}=\gamma \mathrm{L}$. Although the absolute magnitude of this force is small, relative to the size of the particle it can be large. For instance, if $\mathrm{n}=100$ and $\mathrm{R}_{\mathrm{lvo}}=10 \mu \mathrm{m}$, particle radius is $0.31 \mu \mathrm{m}$ (Figure 9). If $\gamma=70$ dyne $/ \mathrm{cm}(70 \mathrm{mN} / \mathrm{m})$ and solid density is $2.5 \mathrm{~g} / \mathrm{cm}^{3}\left(2500 \mathrm{~kg} / \mathrm{m}^{3}\right), \mathrm{F}_{\mathrm{s}}$ is $9,700,00$ times the force of gravity on the particle. 
If the cylindrical particle deforms to spread this stress at the point of contact between solids over an area $1 / 10$ as wide as the particle diameter (i.e., area of contact $=0.2$ $\left.R_{p} L\right)$, the pressure on this area of contact would be $1.14 \mathrm{MPa}(166 \mathrm{psi})$. If the area of contact were smaller, this pressure would be higher, and vice versa.

This force suggests that an enormous energy benefit would ensue from expelling a solid particle and allowing the rest of the armor to relax, as in Figure 4b. This comparison is made below. Our analysis assumes that the solids can freely slide and roll past each other; i.e., that the solids do not bond or adhere to each other. However, the force between particles can lead to significant pressures at the point of contact, which could drive dissolution/precipitation processes to bond the particles in the armor to each other.

\section{Stability of Armor Under Stress}

Table 1 gives changes in interfacial areas and total energy when one solid is pushed outwards from a symmetric armor under stress as illustrated in Figure 4. Values for $\mathbf{n}=5$, 10,20 and 100 and $\theta=10^{\circ}, 70^{\circ}, 130^{\circ}$ and $170^{\circ}$ are included. For each case except $\theta=$ $130^{\circ}$, two initial states are considered: a slightly shrunken bubble, with a small reduction in capillary pressure, and zero capillary pressure. The first initial state tests whether a bubble would start to expel a solid shortly after starting to shrink, before large stresses build up. In each case this state is represented in Figures $10-18$ by the symbol representing the first decrease in volume from the unstressed state. This initial state is intended to represent an arbitrary, small stress on the system; therefore, only the sign, not the magnitude, of the energy changes in Table 1 are significant in making comparisons beteween different values of $\mathrm{n}$ or $\theta$.

Table 1 indicates that in all cases tested, starting to expel a solid shortly after the bubble starts to shrink does not reduce energy. Expelling a solid from the more-stressed state of zero capillary pressure appears more promising. For $\theta=10^{\circ}$ and $n=5$ or 10 , the bubble expels a solid before the bubble reaches a state of zero $\mathrm{p}_{\mathrm{c}}$ (Figures 10 and 11). For $\theta=10^{\circ}$ and $n=20$ or 100 , after the perturbation, the liquid-vapor interfaces meet on the 
inner surface of the expelled solid, which fully detaches from the interface into the liquid. For $\theta=170^{\circ}$, for all values of $n$ tested, the liquid-vapor interfaces meet at the outer surface of the solids adjacent to the particle pushed outwards in the perturbation: one or more of these particles is expelled inwards from the liquid-vapor interface into the vapor phase. In all of these cases one or more particles is expelled from the armor. For $\theta=130^{\circ}$, bubbles with $n=10$ or 20 solids would spontaneously expel a particle from the armor, but bubbles with $n=5$ or 100 particles would not. This suggests that a bubble armored with less than 100 particles might shrink for a time, expelling solids as needed, until it reached a stable size, below which it would not shrink. For $\theta=70^{\circ}$, expulsion is not favored for any tested value of $n$.

This analysis begs the question of whether expulsion of a particle from the zero- $p_{c}$ state could be initiated from a small perturbation. Resolving this issue would require analysis of a smaller perturbation from the zero- $p_{c}$ state.

That extremely stressed, armored bubbles should not in all cases expel particles to relieve stress is remarkable. It is possible that they do so, but by a perturbation different from that tested here. The perturbed state assumed here, illustrated schematically in Figure $4 \mathrm{~b}$, is not itself at equilibrium: as drawn, $(\mathrm{n}-3)$ particles, on the new, shrunken circular perimeter, have zero net capillary force (Figure 7), but the expelled particle and its neighbors would not be in static equilibrium. Thus this state is not an alternative equilibrium state to the symmetric, stressed state, but an arbitrary alternative state, designed to test whether the initial state minimizes energy.

Table 1 makes clear that in many cases overall surface energy increases with the proposed perturbation. Since neighboring solids all touch both before and after the perturbation, the perimeter of the armored bubble, as reflected in the path between centers of the solid particles, is unchanged by the perturbation.

Energy would be reduced if the bubble were to shrink sufficiently (losing gas to the liquid or to vapor above the liquid in the tank) and expel a solid completely, immersing it 
fully in either liquid (for $\theta \leq 90^{\circ}$ ) or vapor (for $\theta \geq 90^{\circ}$ ). The implication of Table 1 is that in many cases the bubble cannot reach this lower-energy state by a succession of small changes, continuously reducing its energy in the process.

Exactly how the process of expelling a particle might end is complex in some cases. Figure 19 illustrates that the expulsion might terminate with the solid particle pushed outside the perimeter of the bubble but still attached to it by the liquid-vapor interface. This does not happen if $\theta$ is sufficiently small or large; instead, a solid detaches completely. Moreover, once the solid is pushed outside the perimeter of the armor, the curvature of the liquid-vapor interface is governed by the geometry of the ring of (n-1) particles left in the armor. In other words, the radius of the liquid-vapor interface is governed by the (n-1) particles remaining, as though the other particle had been expelled completely. The radius of this ring is less than that of the original armored bubble; i.e., capillary pressure has increased (Eq. 2), and the bubble can continue to shrink.

Several factors not considered here could prevent expulsion of a particle even where predicted by this theory. Expulsion requires that the particles slide along the surface of one neighboring solid and either slide or roll along the surface of the other neighbor. Surface roughness or adhesion, not considered here, could prevent this. Angular particle shapes could make this sliding more difficult. Purely attractive short-range forces between particle centers would not affect the sliding process, since the particles are always touching - i.e., always at the same distance from their neighbors. Deformation of particles under stress at their points of contact might make sliding difficult. So could, of course, physical or chemical bonding of particles due to dissolution/precipitation, enhanced by the elevated pressures at their points of contact. Contact-angle hysteresis due to surface roughness or other causes could prevent a bubble from adjusting to a new-lower energy state and ejecting a solid particle.

An additional complication present in three-dimensions, not accounted for in this 2D model or other simplified 3D models, ${ }^{10,11}$ is defects in the packing of particles on the 
bubble surface. In general, even with identical, spherical particles, the perfect hexagonal packing illustrated in Figure 2 is not possible. Along defects the number of particle-particle contacts is reduced, their angles altered, and the open patches of interface between particles larger than illustrated in Figure 2a. The effect of defects on particle packing and armor stress and stability are likely to be complex.

\section{CONCLUSIONS}

1. Experiments with $\mathrm{CO}_{2}$ dissolved in water suggest that PMMA particles can stabilize small bubbles in water for periods of up to several weeks under conditions where the water is unsaturated with respect to $\mathrm{CO}_{2}$. It is not clear how unsaturated the liquid was in this experiment. Similar results were suggested in a previous study using nitrogen bubbles in synthetic Hanford waste.

2. Theoretical calculations show how a coating of solids can stabilize a bubble at zero or even negative capillary pressure. Substantial reduction in capillary pressure is not possible unless $\theta$ is sufficiently greater than zero. In cases of substantially reduced capillary pressure, the stresses on the solids, which can be estimated using Eq. 12, can be large, especially for tiny bubbles and smaller solid particles. The stresses at solidsolid contacts might drive dissolution and precipitation of solid around the points of contact, sintering the solids into a rigid framework.

3. An armor of solid particles does not necessarily solve stability issues relating to bubble density. The density of an armored bubble decreases with pressure as does that of a bubble with no solids, so such a bubble would expand and rise further if perturbed upwards in the tank. However, changes in capillary pressure could drive mass transfer to shrink the bubble as it expands; whether this mechanism would prevent bubble movement depends on the relative rates of flow and of mass transfer.

4. Energy calculations concerning a perturbation toward expelling a solid particle indicate that slightly shrunken bubbles do not expel solids to relieve stress on the armor, but 
more shrunken bubbles might do so. For at least one case, it appears that for a given solid particle size, there may be a range of bubble sizes in which the bubble can shrink and continuously expel solids as it does so, but that this process stops at a minimum size below which the bubble does not shrink further.

5. The energy calculations are preliminary. They are limited to one perturbation toward expelling a particle; it is possible that bubble sizes found to be stable by this analysis might expel particles in other ways. However, the analysis also leaves out several mechanisms that could make expulsion of particles more difficult: particle deformation, surface roughness, contact-angle hysteresis, and adhesion or physical bonding between adjacent particles. Thus it is possible that cases found to be unstable by this analysis might be stabilized by these factors.

\section{SYMBOLS}

$A_{i j} \quad$ area of surface between phases $i$ and $j$

$F_{S}$ hard-sphere repulsive force between adjacent solid particles (Figure 6)

$F_{y c}$ inward radial force on solid particle (Figure 6)

$\mathrm{L}$ length of bubble and solids in $\mathrm{z}$ direction, perpendicular to plane of Figure 3

n number of particles in armor around bubble

$\mathrm{p}_{\mathrm{c}} \quad$ capillary pressure (Eqs. 1, 2)

pl liquid-phase pressure

pv pressure in the bubble

$R_{1 v}$ radius of curvature of the liquid-vapor interface around the bubble

$\mathbf{R}_{\text {lvo }}$ radius of bubble before addition of solid particles

$\mathbf{R}_{\mathbf{l v i}}$ radius of bubble with close-fitting, but unstressed, armor

$\mathbf{R}_{\mathbf{p}} \quad$ radius of solid particle

$\mathrm{U}$ energy (Eqs. 3, 6)

$\mathrm{V}$ volume of bubble

$V_{i}$ initial volume of bubble 
$\gamma \quad$ (with no subscripts) liquid-vapor surface tension (also $\gamma_{\mathrm{v}}$ )

$\gamma_{i j}$ surface tension or surface energy of interface between phases $i$ and $j$

$\delta$ distance of separation between solid particles at which hard-sphere repulsion acts (Figure 2)

$\theta$ contact angle

\section{Subscripts}

D dimensionless

i initial

1 liquid phase

$s$ solid phase

v vapor phase

\section{REFERENCES}

1. Allemann, R. T., and T. M. Burke, D. A. Reynolds, and D. E. Simpson, "Assessment of Gas Accumulation and Retention - Tank 241-SY-101," WHC-EP0576, Westinghouse Hanford Company, Richland, Washington, 1993.

2. Gauglitz, P. A., S. D. Rassat, M. R. Powell, R. R. Shah, and L. A. Mahoney, "Gas Bubble Retention and Its Effects on Waste Properties: Retention Mechanisms, Viscosity, and Tensile and Shear Strengths," PNL-10740, Pacific Northwest National Laboratory, Richland, Washington, August 1995.

3. Gauglitz, P. A., S. D. Rassat, J. H. Konynenbelt, and D. P. Mendoza, "Mechanisms of Gas Bubble Retention and Release: Results for Hanford Waste Tanks 241-S-102 and 241-SY-103 and Single-Shell Tank Simulants," PNNL-11298, Pacific Northwest National Laboratory, Richland, Washington, 1996.

4. Bryan, S. A., L. R. Pederson, and R. D. Sheele, Proc. Waste Management ' 92 Conference, Tucson, Arizona, March 1992, p. 829. 
5. Rossen, W. R., and S. K. Das, "Mechanisms of Stability of Armored Bubbles: FY 1995 Progress Report," PNNL-11133, Pacific Northwest National Laboratory, Richland, Washington, 1996.

6. Adamson, A. W., "Physical Chemistry of Surfaces," John Wiley and Sons, New York, 1990.

7. Modell, M., and R. C. Reid, "Thermodynamics and Its Applications," Prentice-Hall, Englewood Cliffs, NJ, 1974.

8. Kelly, E. G., and D. J. Spottiswood, "Introduction to Mineral Processing," John Wiley and Sons, New York, 1982.

9. Houghton, G., A. M. McLean, and P. D. Ritchie, Chem. Eng. Sci. 6, 132 (1957).

10. Levine, S., and B. D. Bowen, Colloids and Surfaces 59, 377 (1991).

11. Levine, S., and B. D. Bowen, Colloids and Surfaces A70, 33 (1993).

12. Rossen, W. R., J. Colloid Interface Sci. 136, 1 (1990). 


\section{APPENDIX}

\section{CALCULATION OF BUBBLE AND ARMOR GEOMETRY}




\section{APPENDIX: CALCULATION OF BUBBLE AND ARMOR GEOMETRY}

The solids form a circular ring around the center of the bubble for both a closepacked, unstressed armor (Figure 3) and stressed, symmetric armor (Figure 4a). For the unstressed armor the liquid-vapor interface is a circle of radius $R_{I v i}$ that intersects the particle surfaces with the given contact angle $\theta$. The initial volume of the bubble $V_{i}$ must account for the volume occupied within the bubble by the cylindrical solids. For an armored bubble with a small number $\mathbf{n}$ of relatively large particles, the solids take up a significant fraction of apparent bubble volume, as illustrated in Figure 3. To put it differently, a bubble with a given gas volume $V_{i}$ expands its radius significantly as it acquires an armor of large particles. In the process, its radius of curvature increases from $R_{\text {lvo }} \equiv\left(3 V_{i} / 4 \pi\right)^{1 / 3}$ to a larger value $R_{\text {lvi }}$, calculated accounting for volume occupied by solids. Thus capillary pressure decreases (Eq. 2) as a bubble acquires a solid armor, as shown in Figure 8, due to the apparent increase in its volume, even before the bubble shrinks and puts stress on the armor.

The armor retains its circular shape in the stressed, symmetric case (Figure 4a). As the bubble shrinks, the liquid-vapor interface retreats along the solid surface toward the center of the bubble. For any given point of contact, the liquid-vapor interface must be cylindrical and touch the solids with contact angle $\theta$. Thus for any given point of contact, one can calculate $R_{l v}$ and the new gas volume $V$.

Calculation of energy changes using Eq. 6 proceeds as follows. We examine two initial states: one just slightly stressed (the first decrease in bubble volume V in Figures 1018) and the other with $p_{c D}=0$. For each initial state (Figure $4 a$ ), we seek the perturbed state (Figure $4 b$ ) with the same volume. Since the magnitude of the initial state of stress varies from case to case (i.e., varying $\theta$ or $n$ ), only the sign of the energy change, which indicates whether the perturbation is favored or not, is of interest, not the magnitude of the energy change. 
The perturbed state (Figure $4 \mathrm{~b}$ ) is computed as follows. (n-1) of the solids form a circular framework as one solid is displaced outwards from this circle by a distance $h$. For any given $h$, the liquid-vapor interfaces all must have the same radius $R_{\mathbf{l v}}$ and contact solids with the given contact angle $\theta$. These positions of contact can be determined from trigonometry. Calculating $\mathrm{V}$ is complex, but follows the same principles as for the unstressed state above. There is a unique $\mathrm{h}$ that gives the same volume as before the perturbation; thus $\mathrm{h}$, and all dependent parameters, are determined by iteration.

The process of shrinking must end when the opposing liquid-vapor interfaces meet either at the innermost point on the solid surface (for $\theta \leq 90^{\circ}$ ) or at a point interior to the armor (for $\theta>90^{\circ}$ ). Figure 20 illustrates these two possibilities schematically. After this point at least one solid would detach from the bubble. Thus this sets the minimum volume to which the bubble can shrink before it expels a solid. However, as shown in Figures 1018 for $\mathrm{n}$ greater than 10 and $\theta$ much greater than zero, the bubble takes strongly negative capillary pressures well before this point is reached. Therefore, probably a bubble never shrinks this far in practice.

In practice, we computed 8 cases between that of an unstressed armor and $\mathrm{p}_{C D}=0$, and 11 cases between $\mathrm{P}_{\mathrm{CD}}=0$ and the minimum bubble volume. Each case is represented by a filled-in symbol on Figures 10-18. 
TABLES 
Table 1.

Energy Change Upon Partially Expelling a Solid Particle From a Stressed Armor

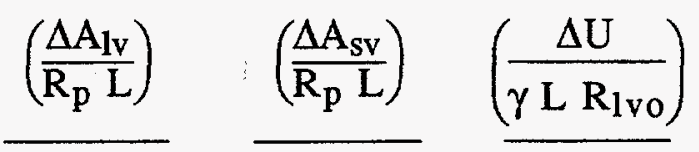

\section{Initial State: Slightly Reduced Volume}

\begin{tabular}{crrl}
$\theta=10^{\circ}$ & \multicolumn{3}{l}{} \\
$n=5$ & -0.288 & 7.602 & 9.083 \\
$n=10$ & -0.258 & 0.355 & 0.038 \\
$n=20$ & -0.042 & 0.551 & 0.088 \\
$n=100$ & 3.417 & 0.524 & 0.121 \\
$\theta=70^{\circ}$ & & & \\
$n=5$ & -0.025 & 0.091 & 0.006 \\
$n=10$ & -0.025 & 0.083 & 0.0015 \\
$n=20$ & -0.025 & 0.081 & 0.0006 \\
$n=100$ & -0.023 & 0.081 & 0.00015 \\
$\theta=170^{\circ}$ & & & \\
$n=5$ & 1.136 & -5.268 & 3.887 \\
$n=10$ & 0.709 & -10.484 & 3.639 \\
$n=20$ & 0.707 & -10.621 & 1.783 \\
$n=100$ & 2.257 & 0.654 & 0.049
\end{tabular}

Initial State: Zero Capillary Pressure

\begin{tabular}{|c|c|c|c|}
\hline \multicolumn{4}{|l|}{$\theta=10^{\circ}$} \\
\hline$n=5$ & (1) & & \\
\hline $\mathrm{n}=10$ & (1) & & \\
\hline $\mathrm{n}=20$ & (2) & & \\
\hline $\begin{aligned} n=100 \\
\theta=70^{\circ}\end{aligned}$ & (2) & & \\
\hline$n=5$ & -0.230 & 0.831 & 0.055 \\
\hline $\mathrm{n}=10$ & 1.691 & 0.751 & 0.035 \\
\hline $\mathrm{n}=20$ & -0.222 & 0.733 & 0.029 \\
\hline $\mathrm{n}=100$ & -0.220 & 0.718 & 0.026 \\
\hline$\theta=130^{\circ}$ & & & \\
\hline $\mathrm{n}=5$ & 1.405 & -0.151 & 1.502 \\
\hline $\mathrm{n}=10$ & 1.193 & 2.106 & -0.160 \\
\hline $\mathrm{n}=20$ & 1.157 & 2.003 & -0.130 \\
\hline $\mathrm{n}=100$ & 1.302 & 1.930 & 0.062 \\
\hline$\theta=170^{\circ}$ & & & \\
\hline $\mathrm{n}=5$ & (2) & & \\
\hline$n=10$ & (2) & & \\
\hline $\begin{array}{l}n=20 \\
n=100\end{array}$ & $\begin{array}{l}\text { (2) } \\
\text { (2) }\end{array}$ & & \\
\hline
\end{tabular}

(1) - initial state not possible: neighboring liquid-vapor interfaces meet

(2) - perturbed state not possible: neighboring liquid-vapor interfaces meet 


\section{FIGURES}




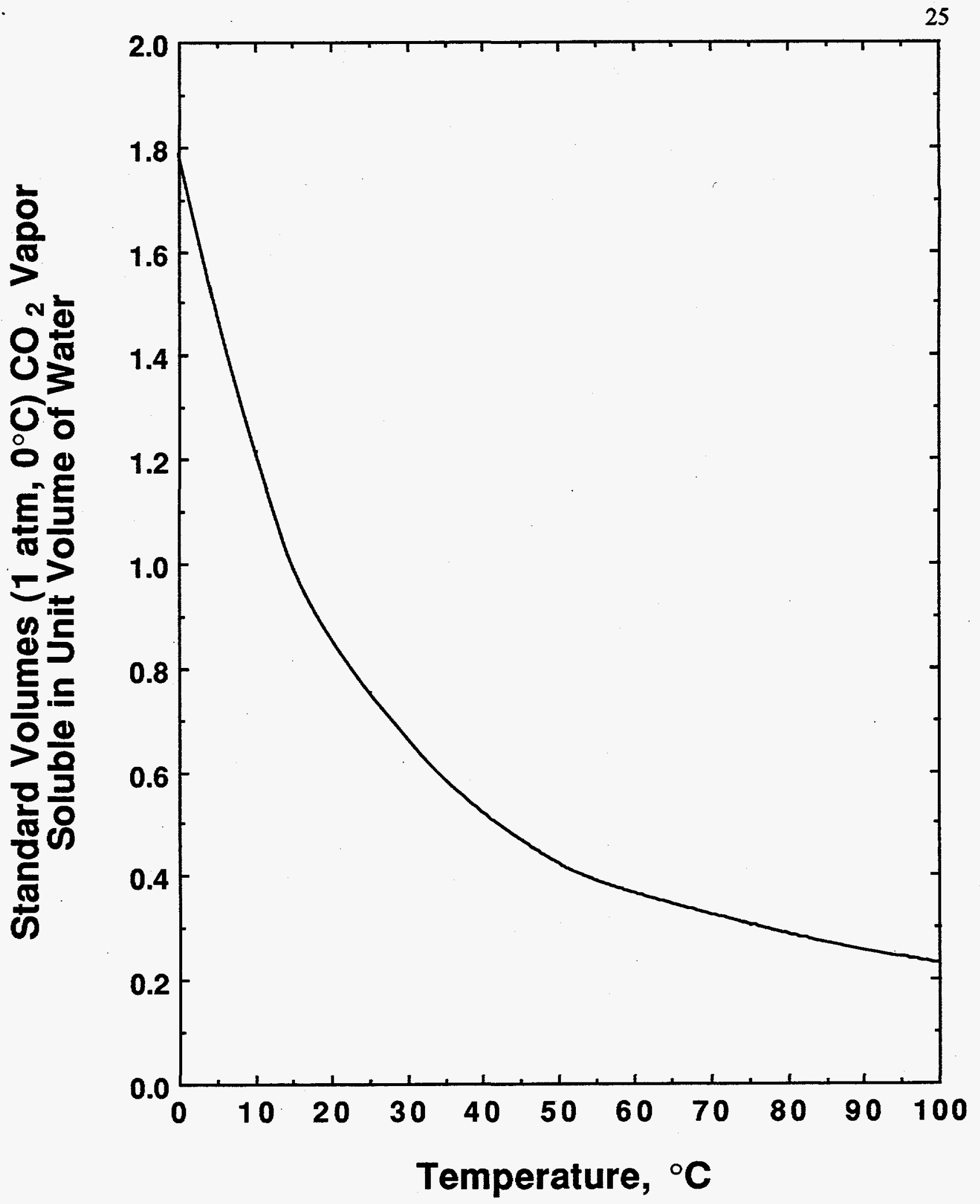

Figure 1. Solubility of $\mathrm{CO}_{2}$ in Water. From Ref. (9) 
a) 3D: (view perpendicular to interface)

b) 2D Model:
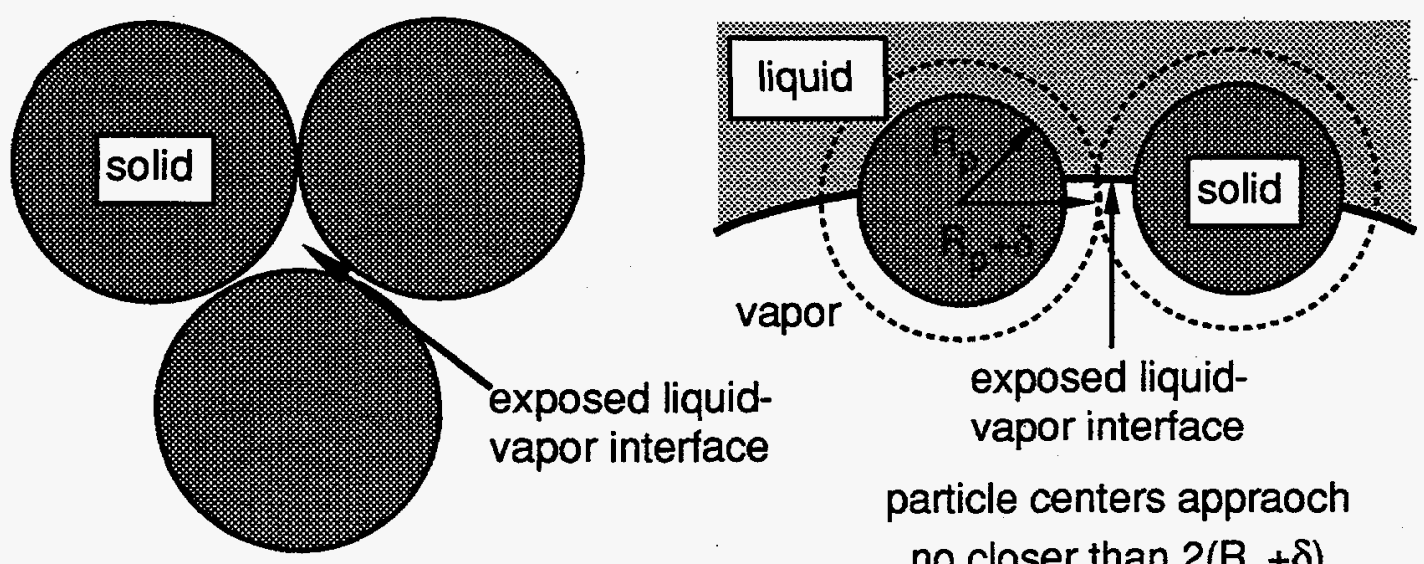

particle centers appraoch no closer than $2\left(R_{p}+\delta\right)$

\section{Figure 2. Gap between solid particles in 3D} and in 2D model

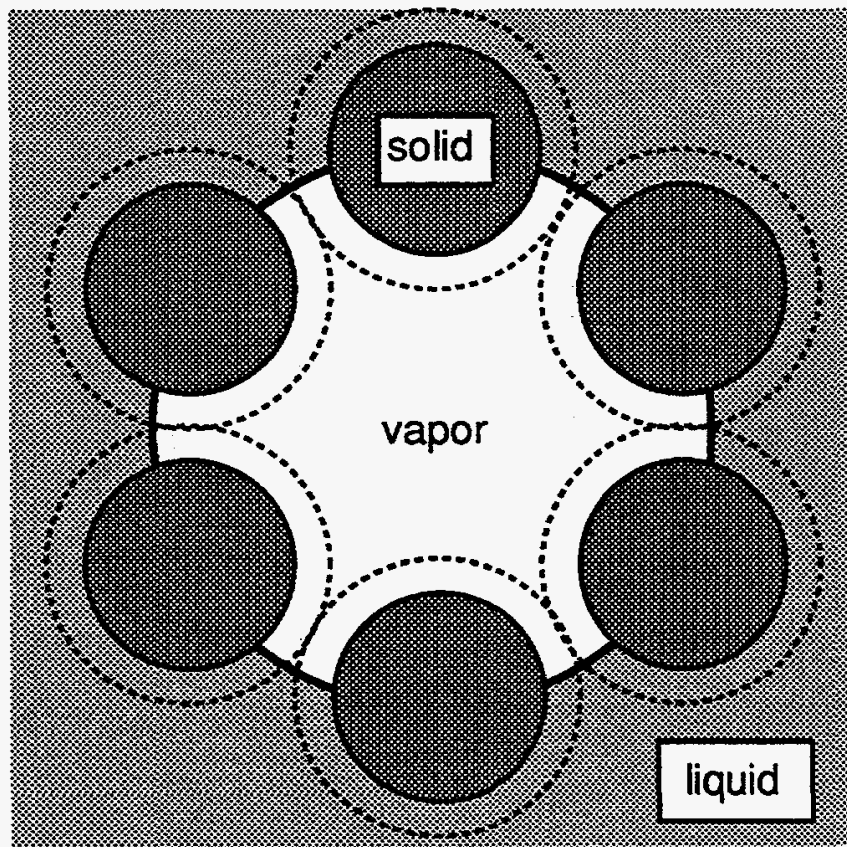

Length $=L$ in $z$ direction (perpendicular to figure)

\section{Figure 3. 2D Model for bubble (schematic)}


a) Stressed state

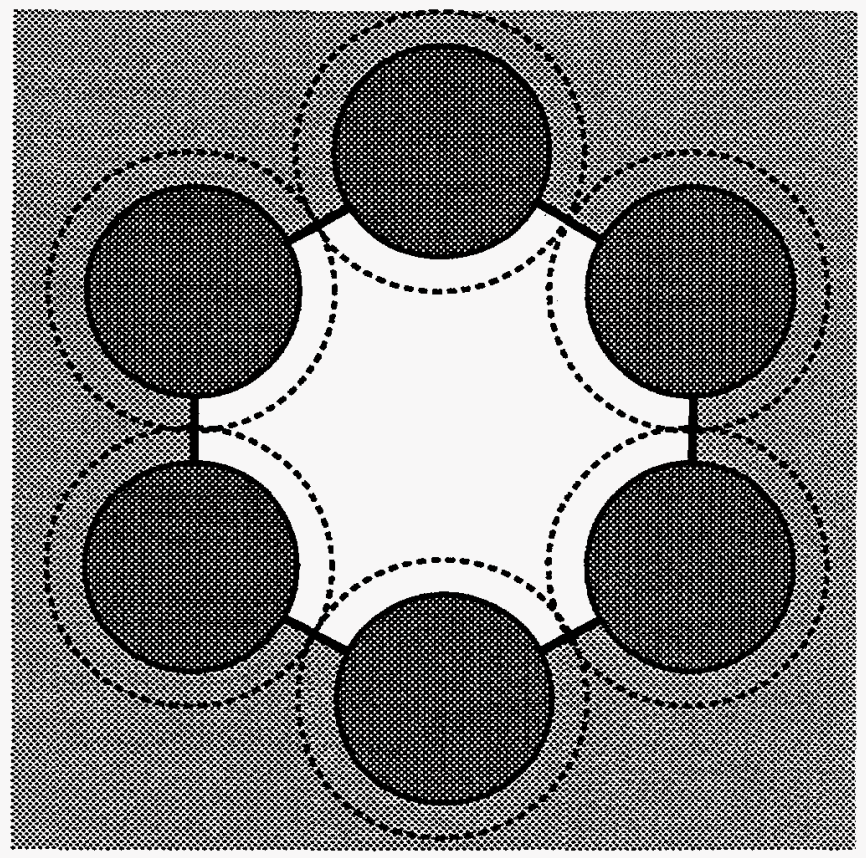

(solids in circular array, but interface distorted) b) State after partially expelling solid particle

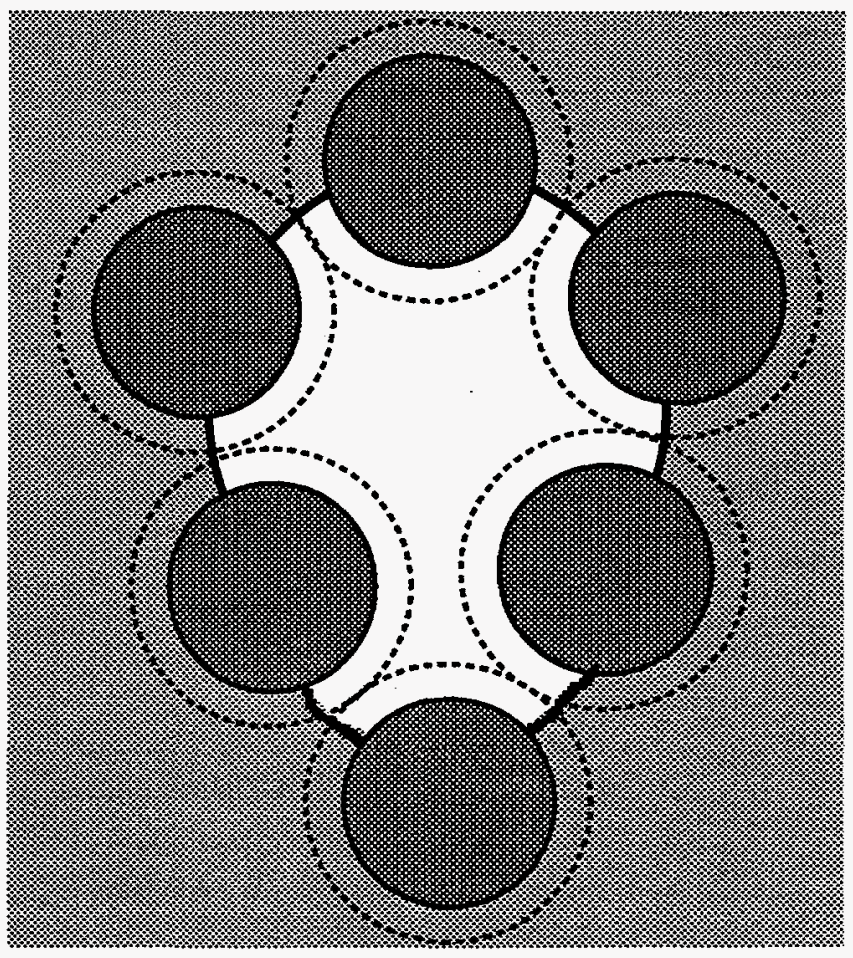

(one solid partially expelled, rest of interface relaxes)

\section{Figure 4. Model for stressed coating and expulsion of solid particle (schematic)}

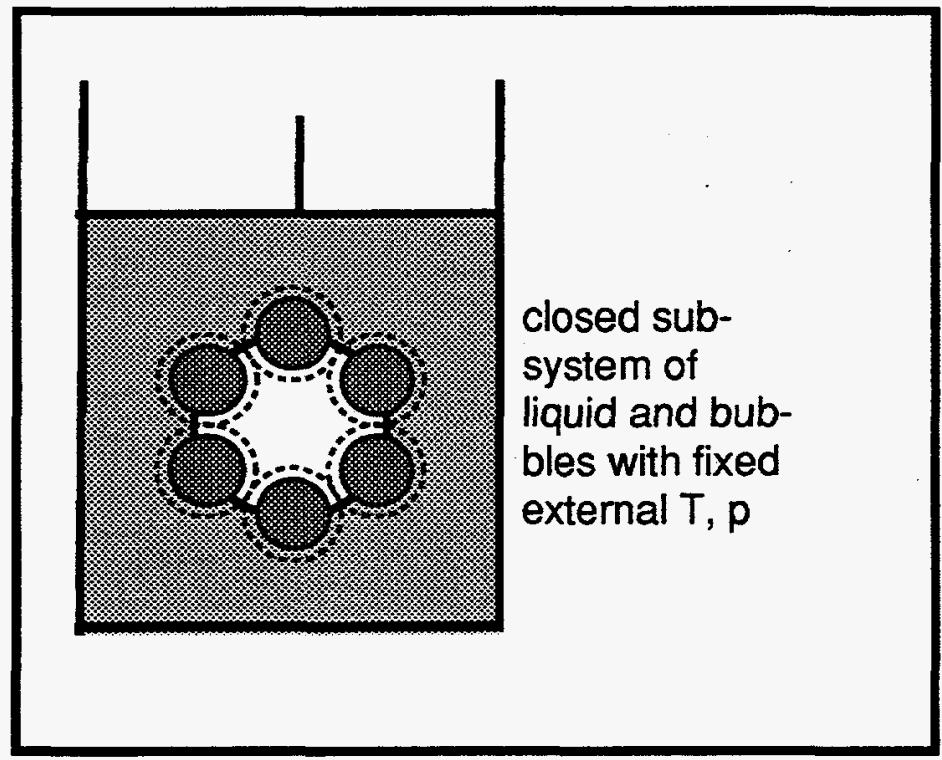

overall system closed and adiabatic, with constant volume

Figure 5. Model for thermodynamic calculations 


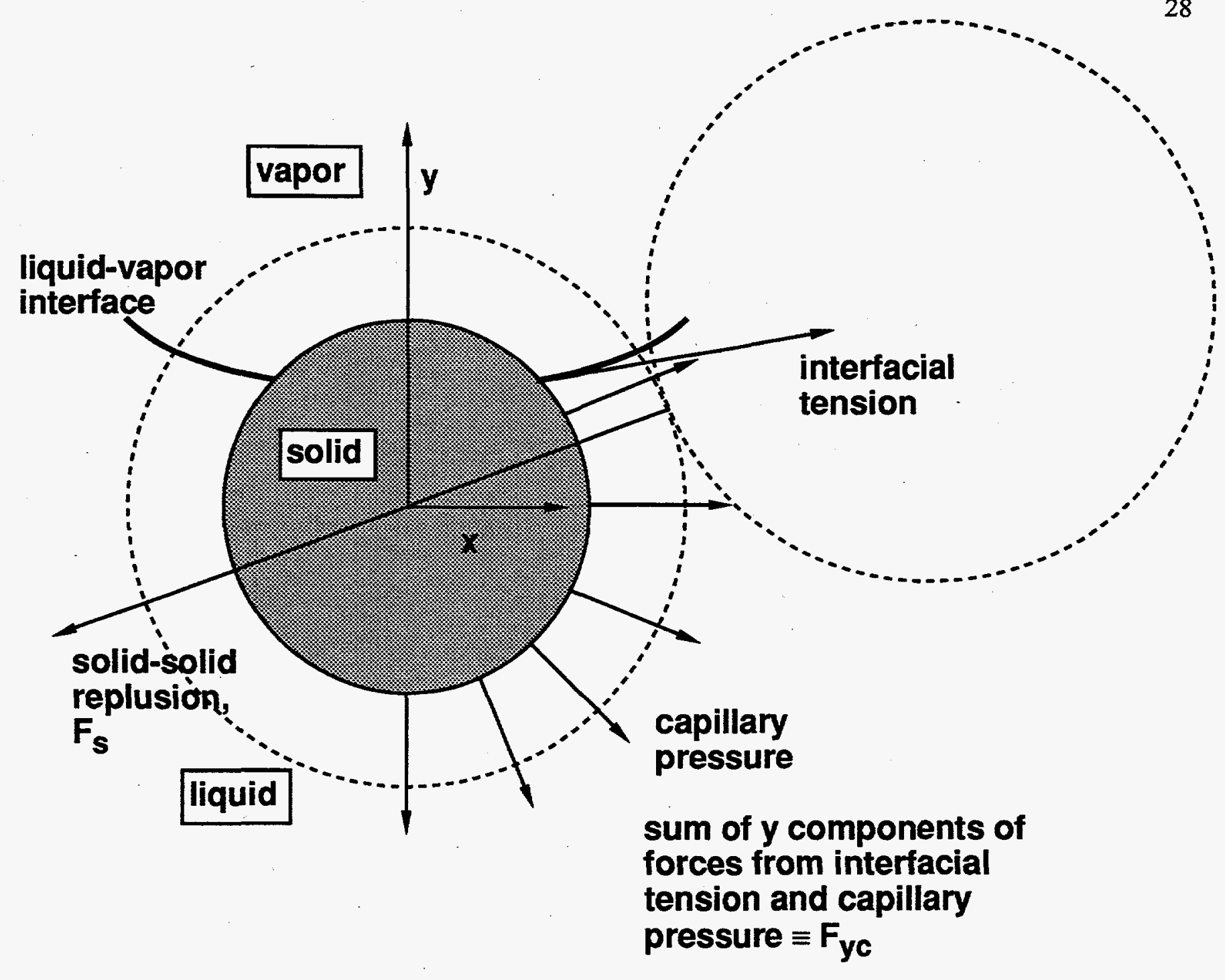

Figure 6. Forces on solid particle (schematic) (Only one half shown; forces from other side of particle are symmetric with those shown.) 


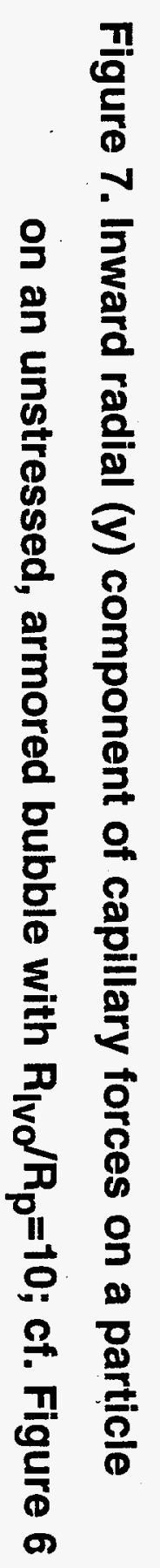

Dimensionless capillary force (force $/ \gamma$ L)
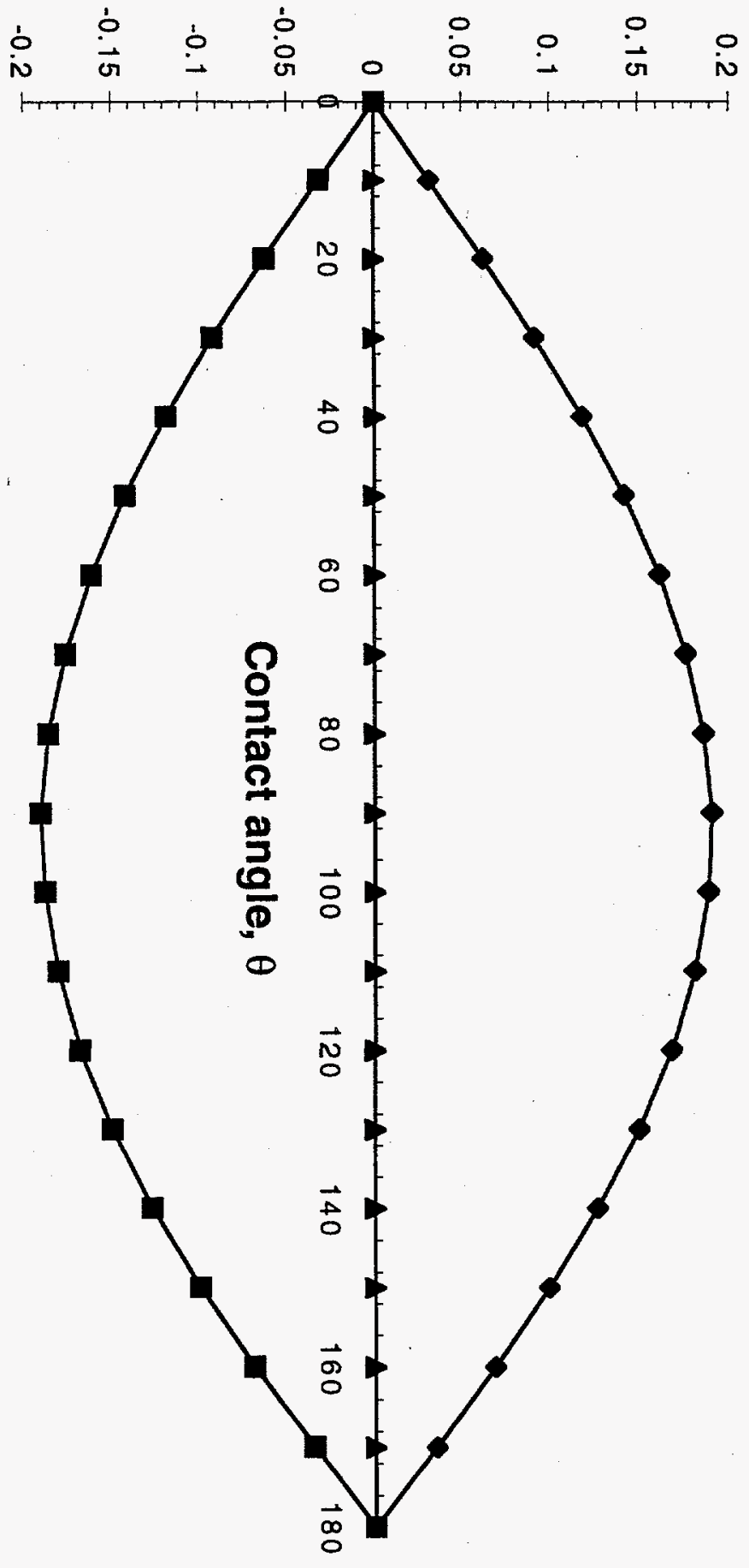

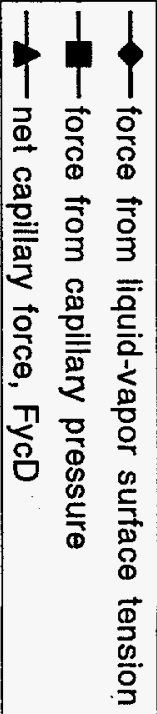




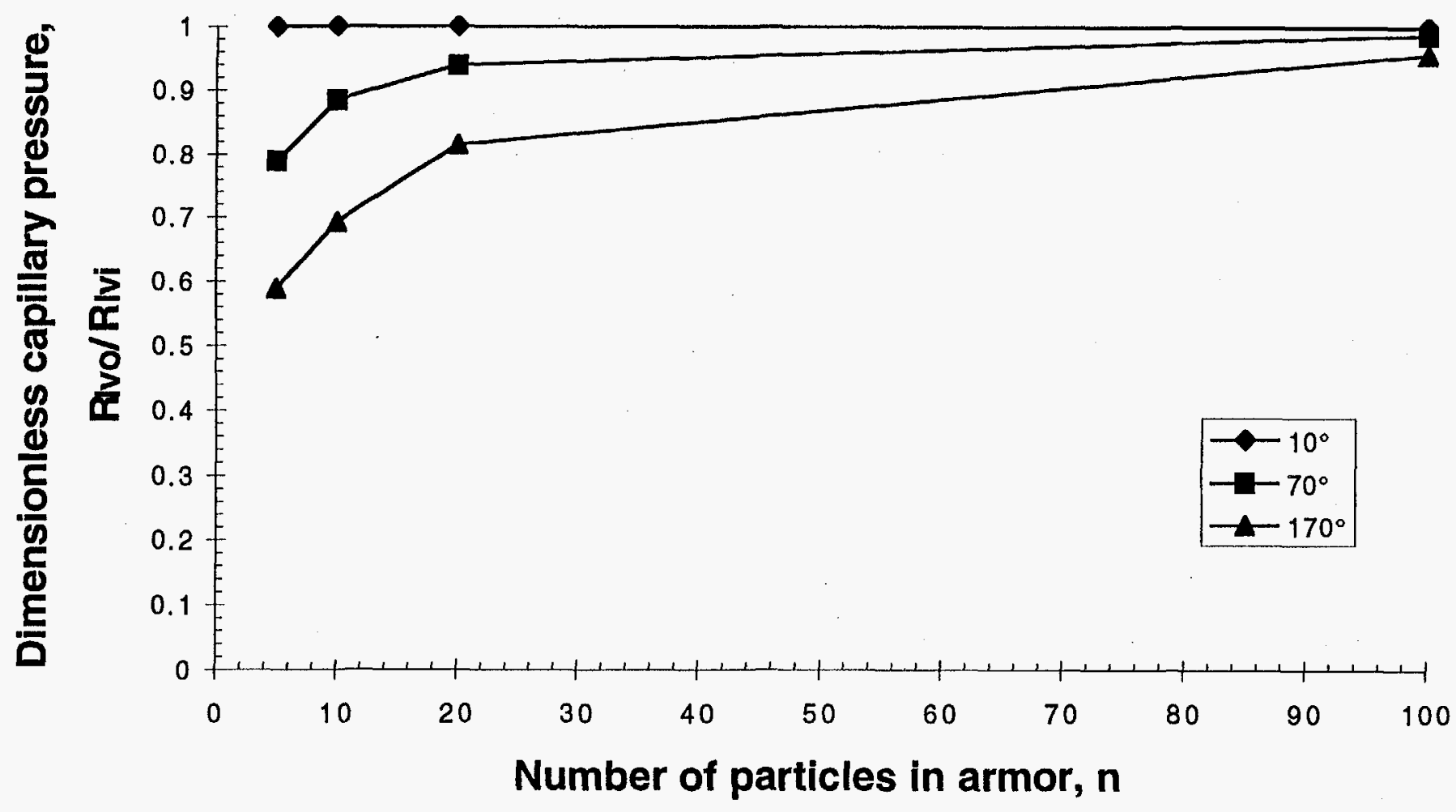

Figure 8. Dimensionless capillary pressure of unstressed, armored bubbles for different values of $\theta$ 


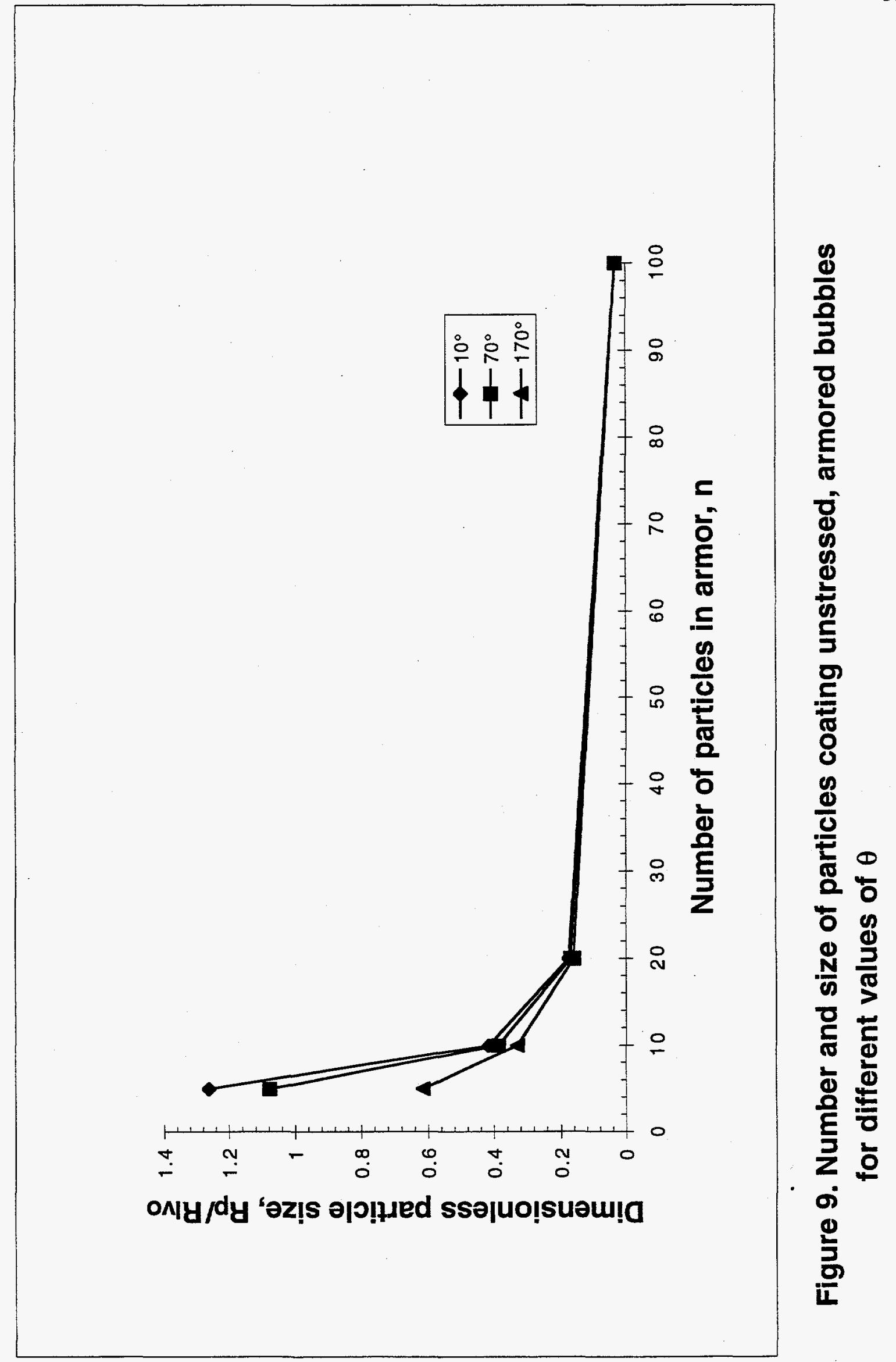




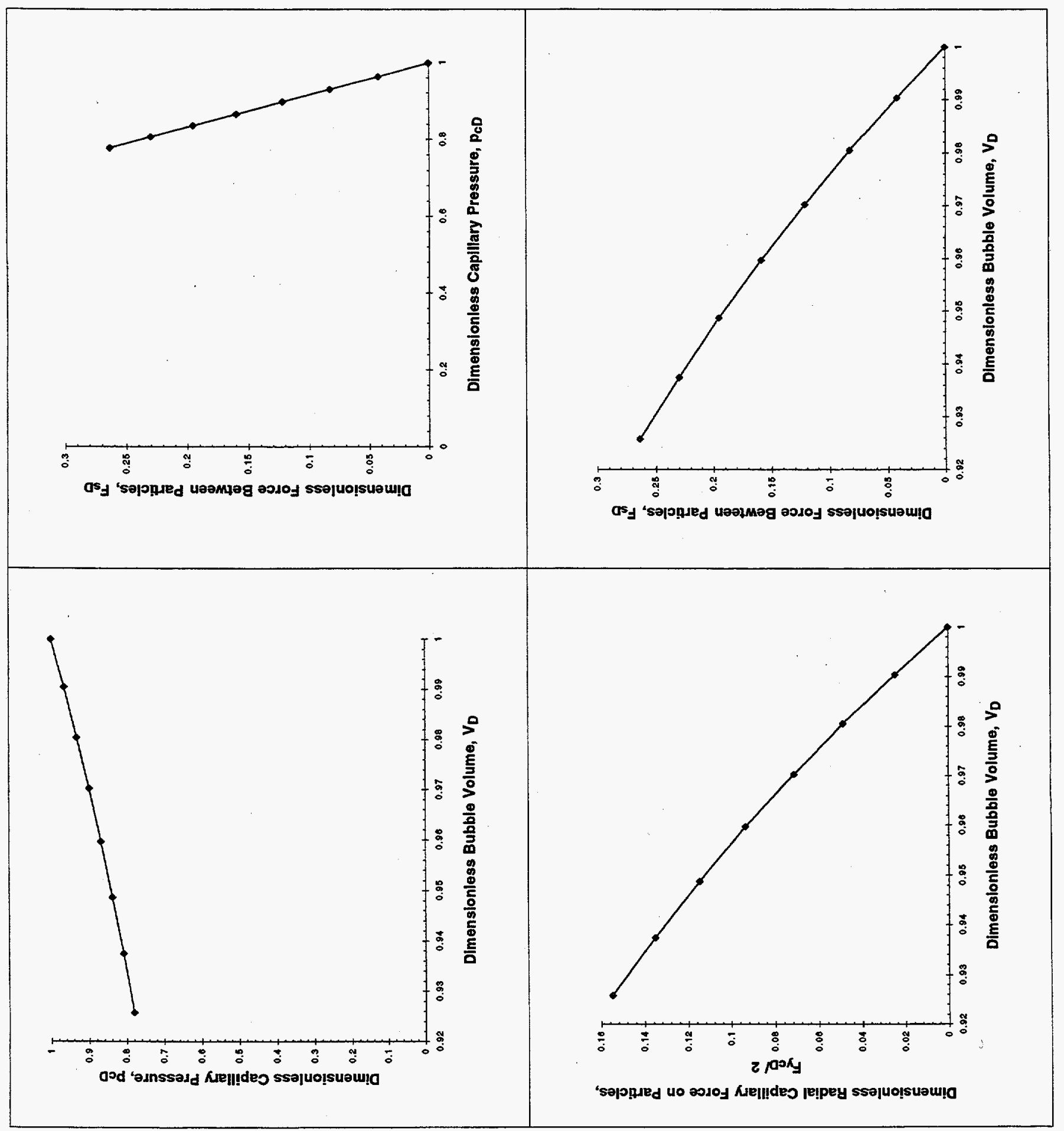

음 


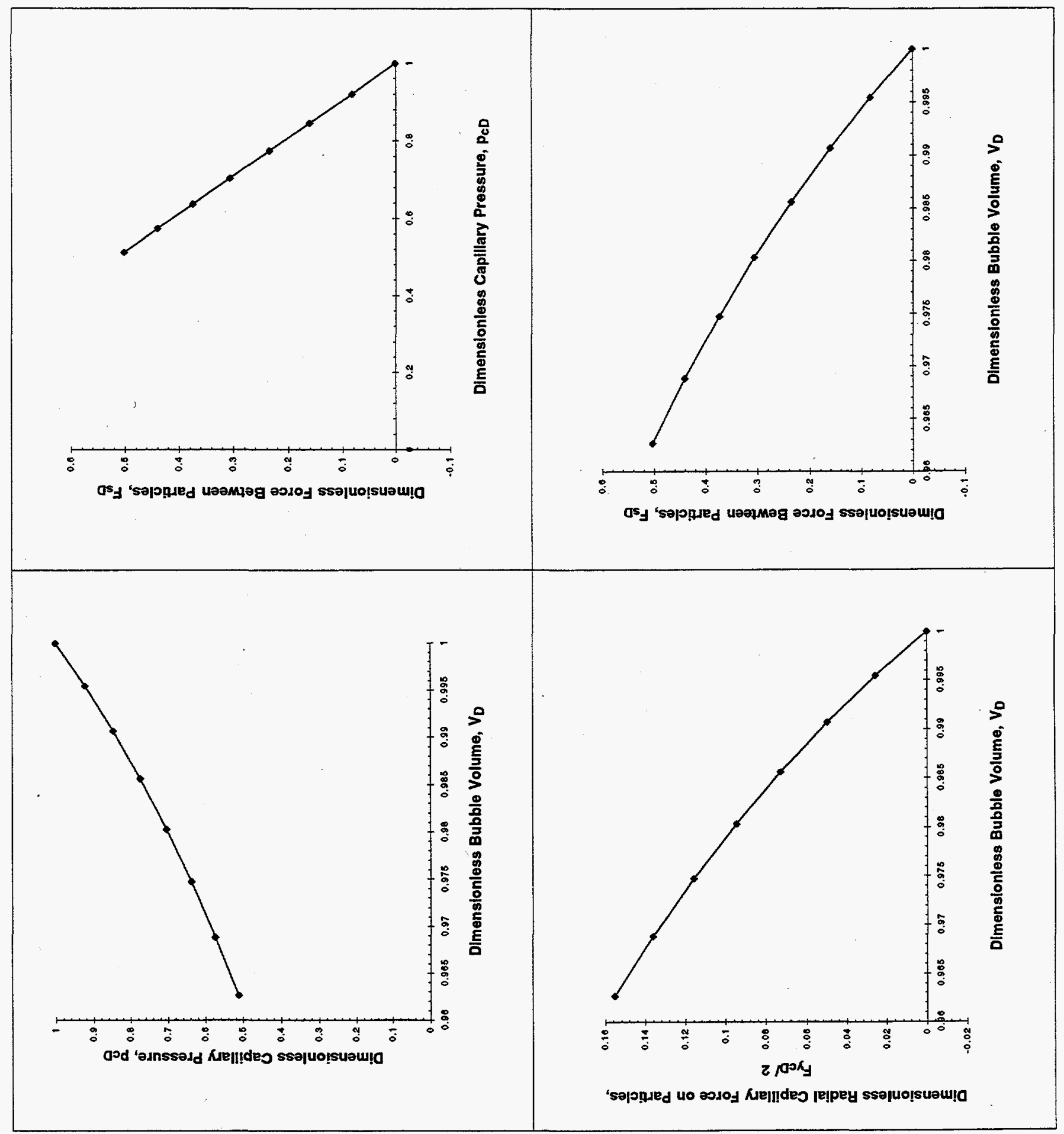

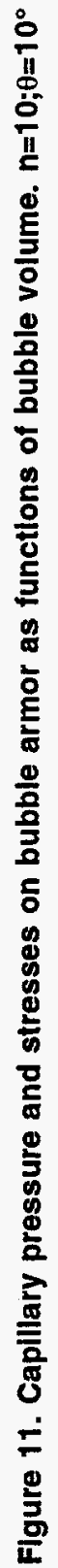




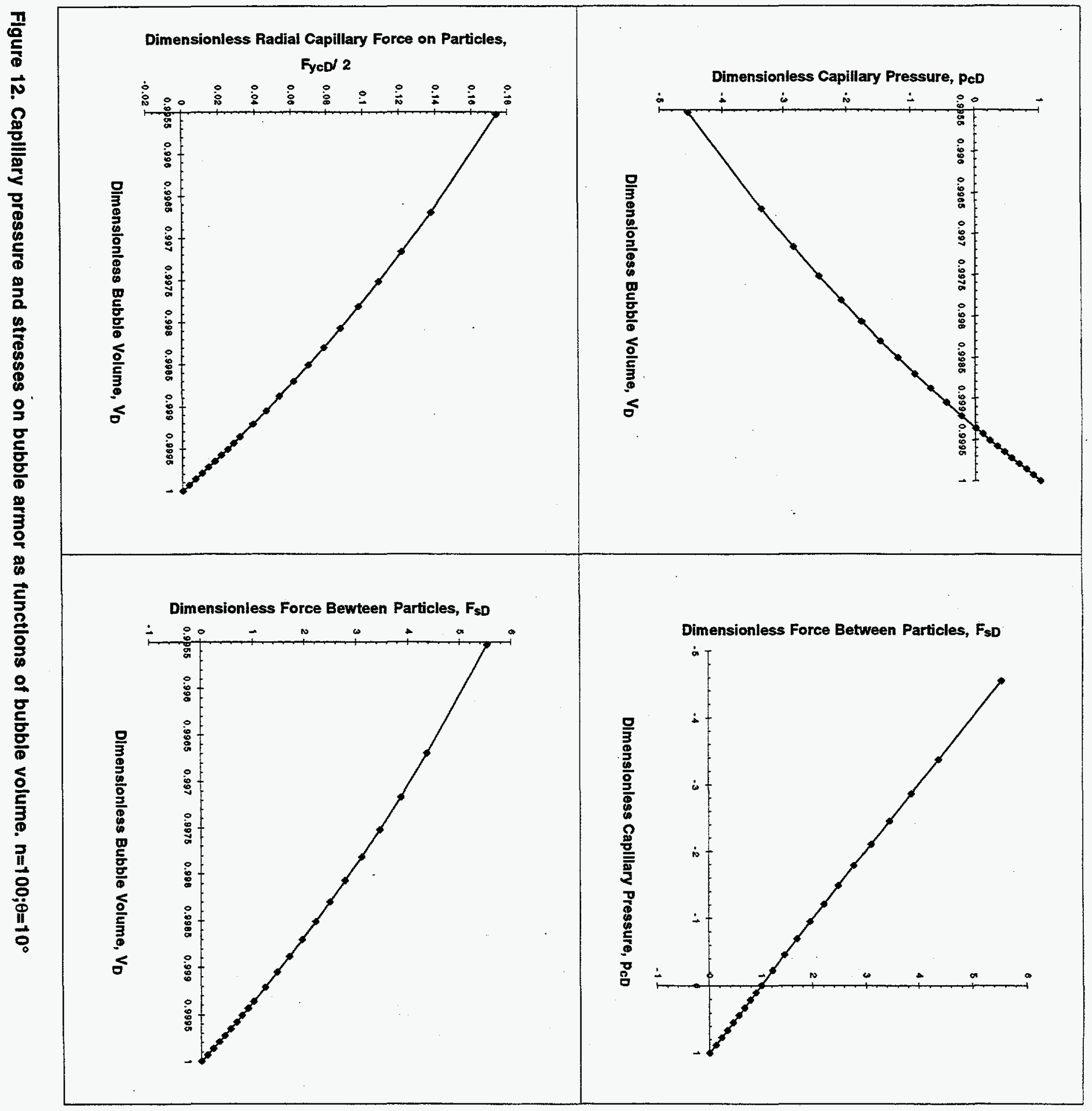




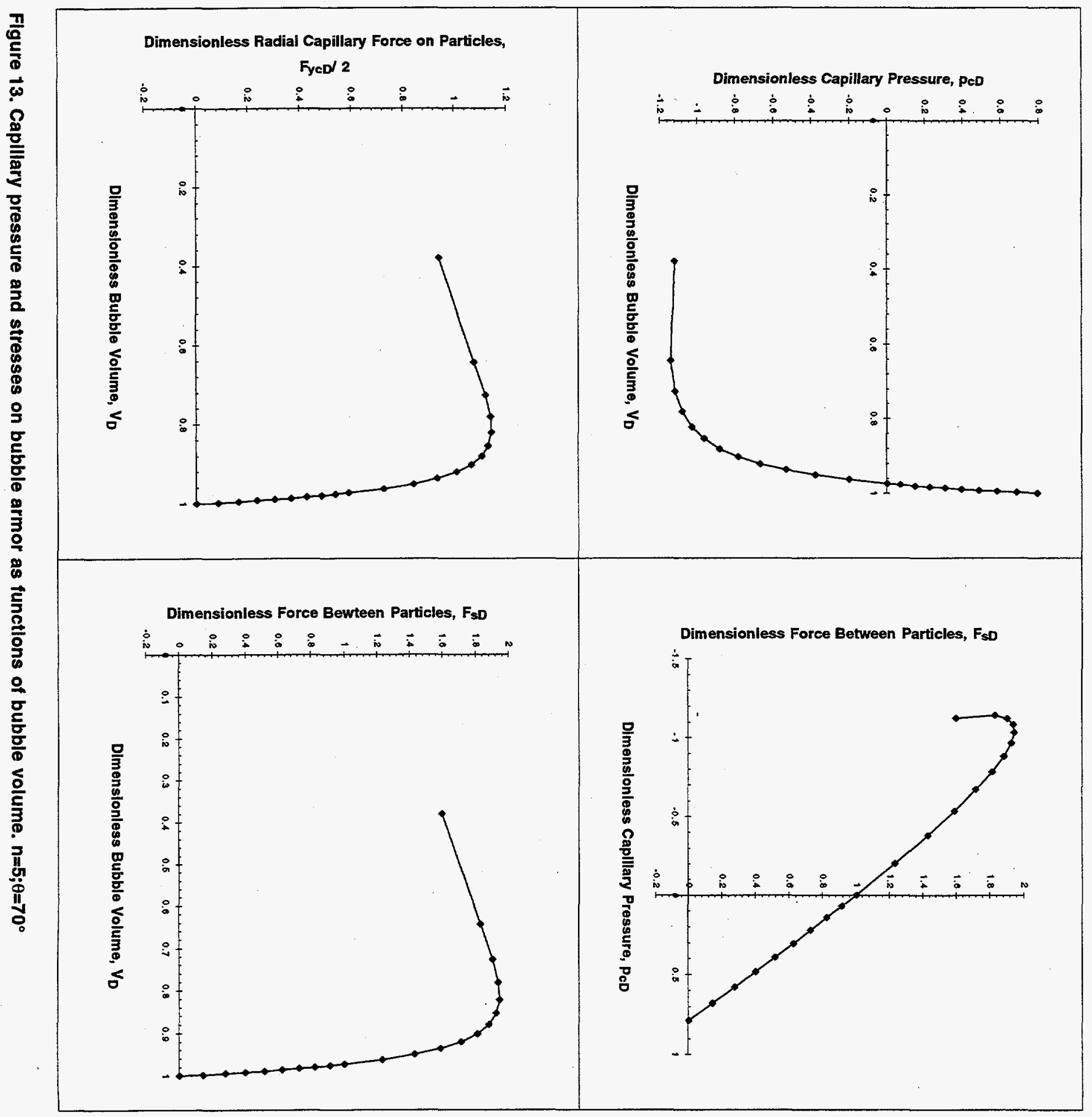

$\Im \mathcal{E}$ 


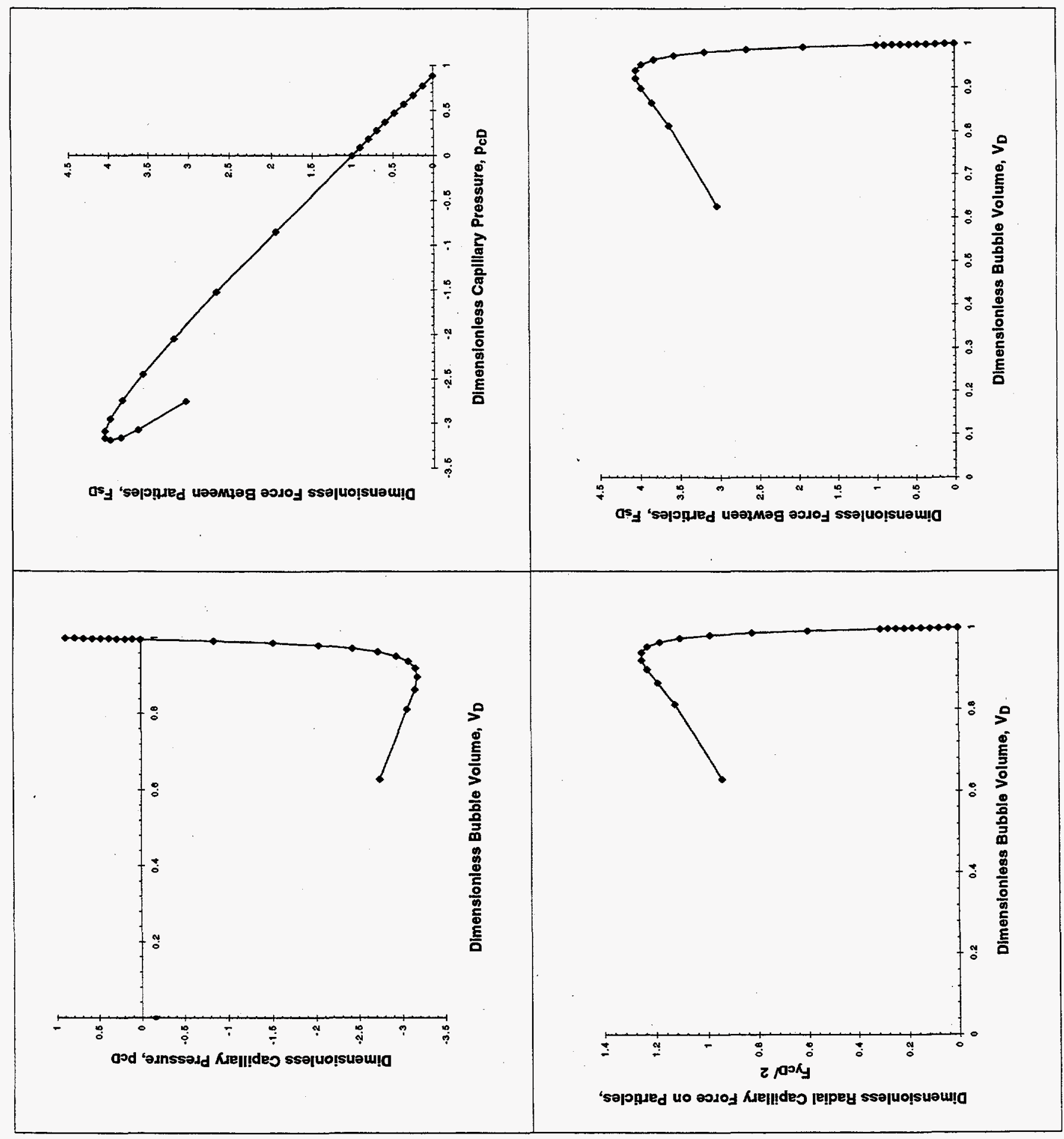

을 


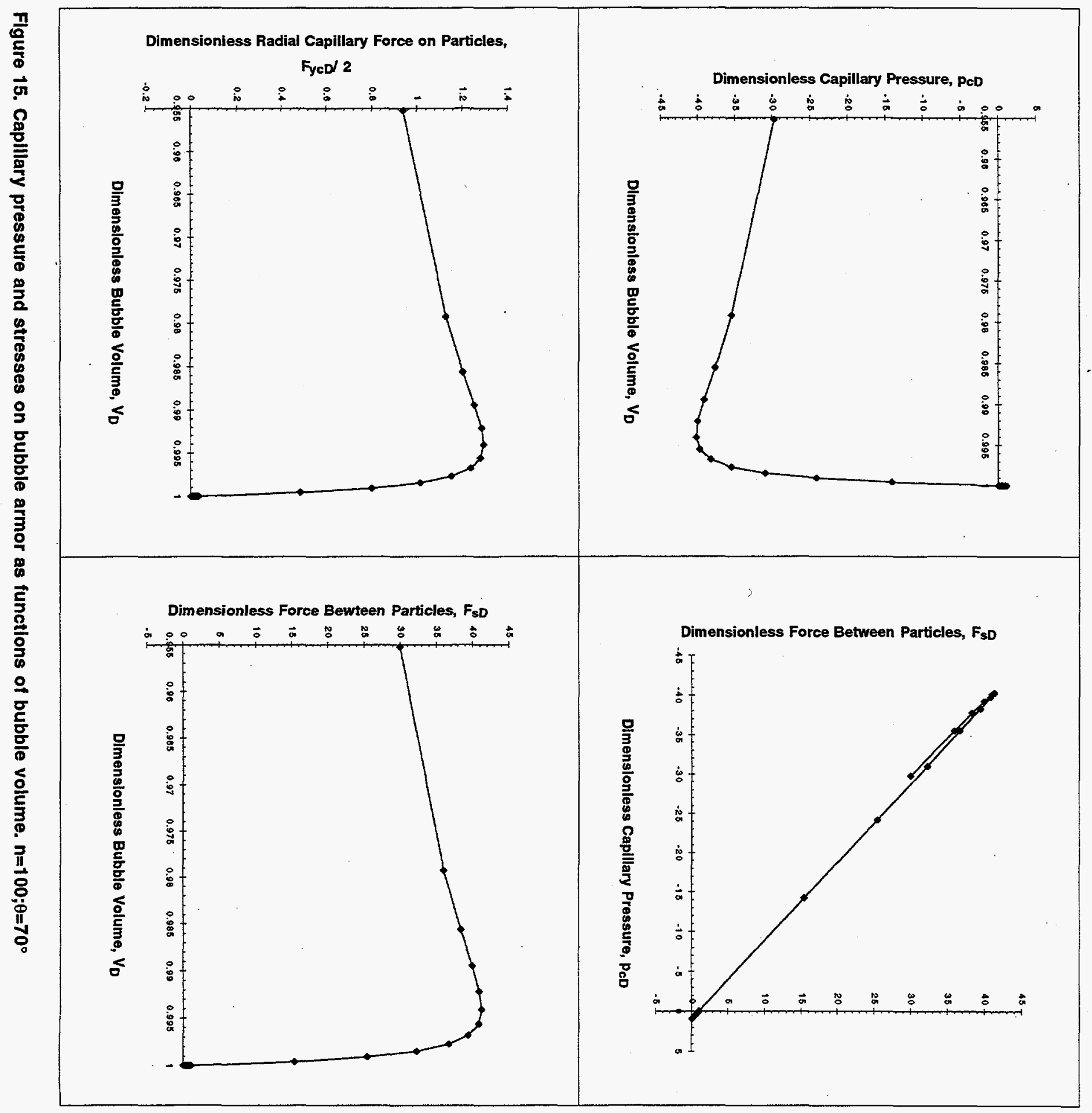




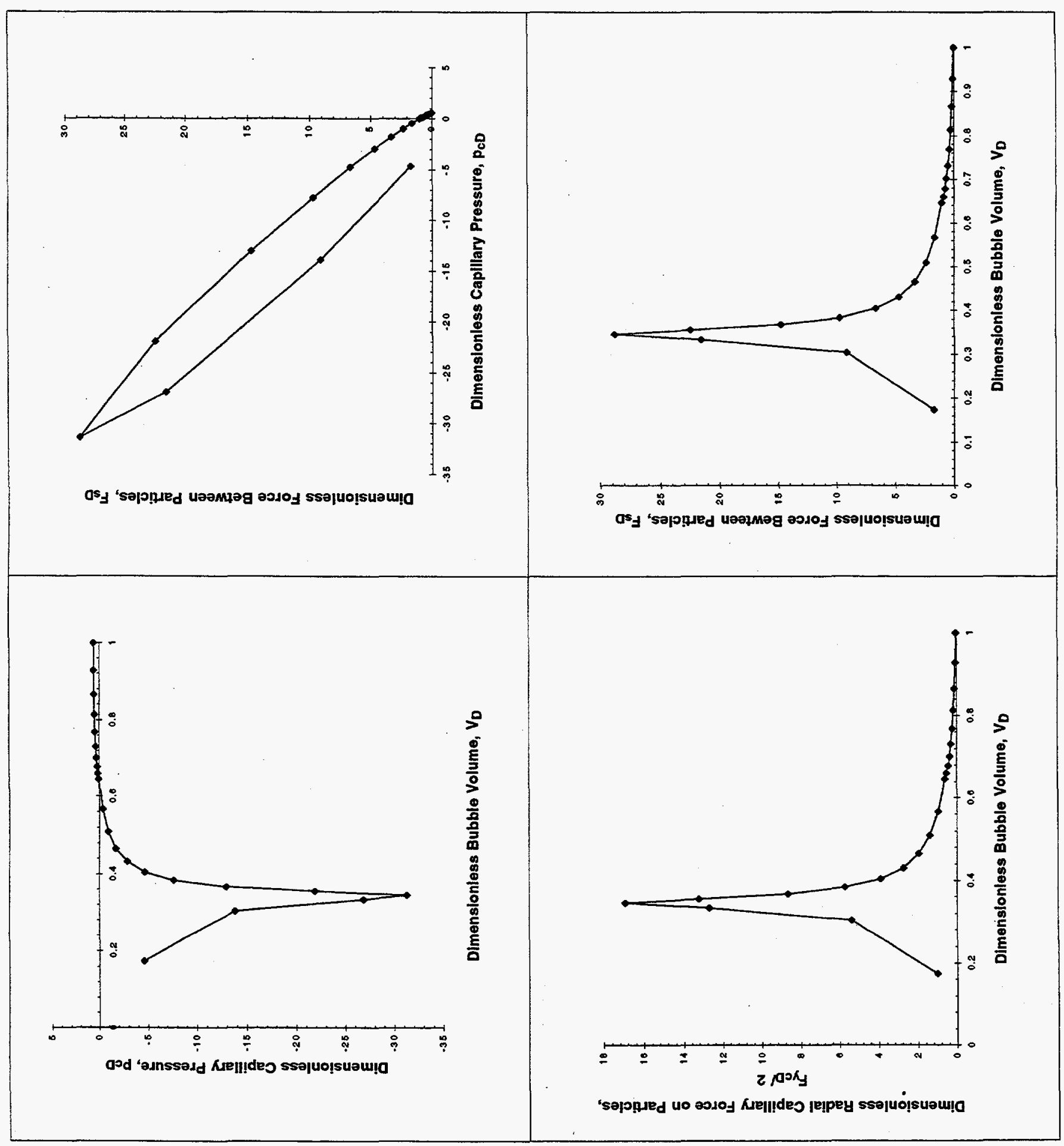

을 


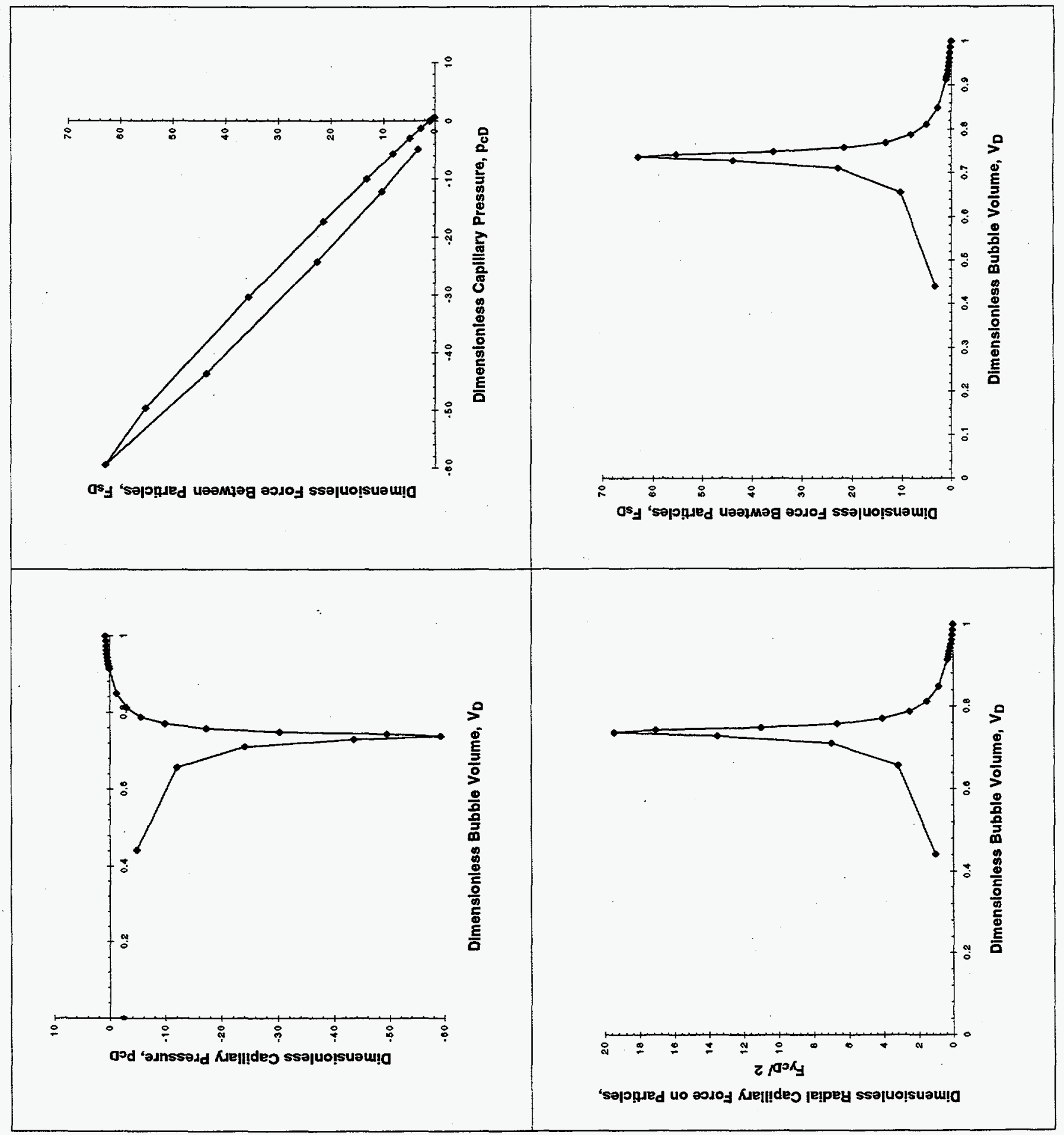

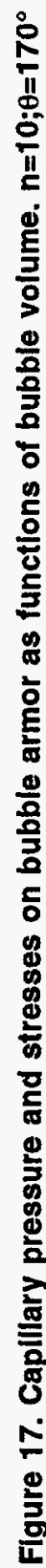




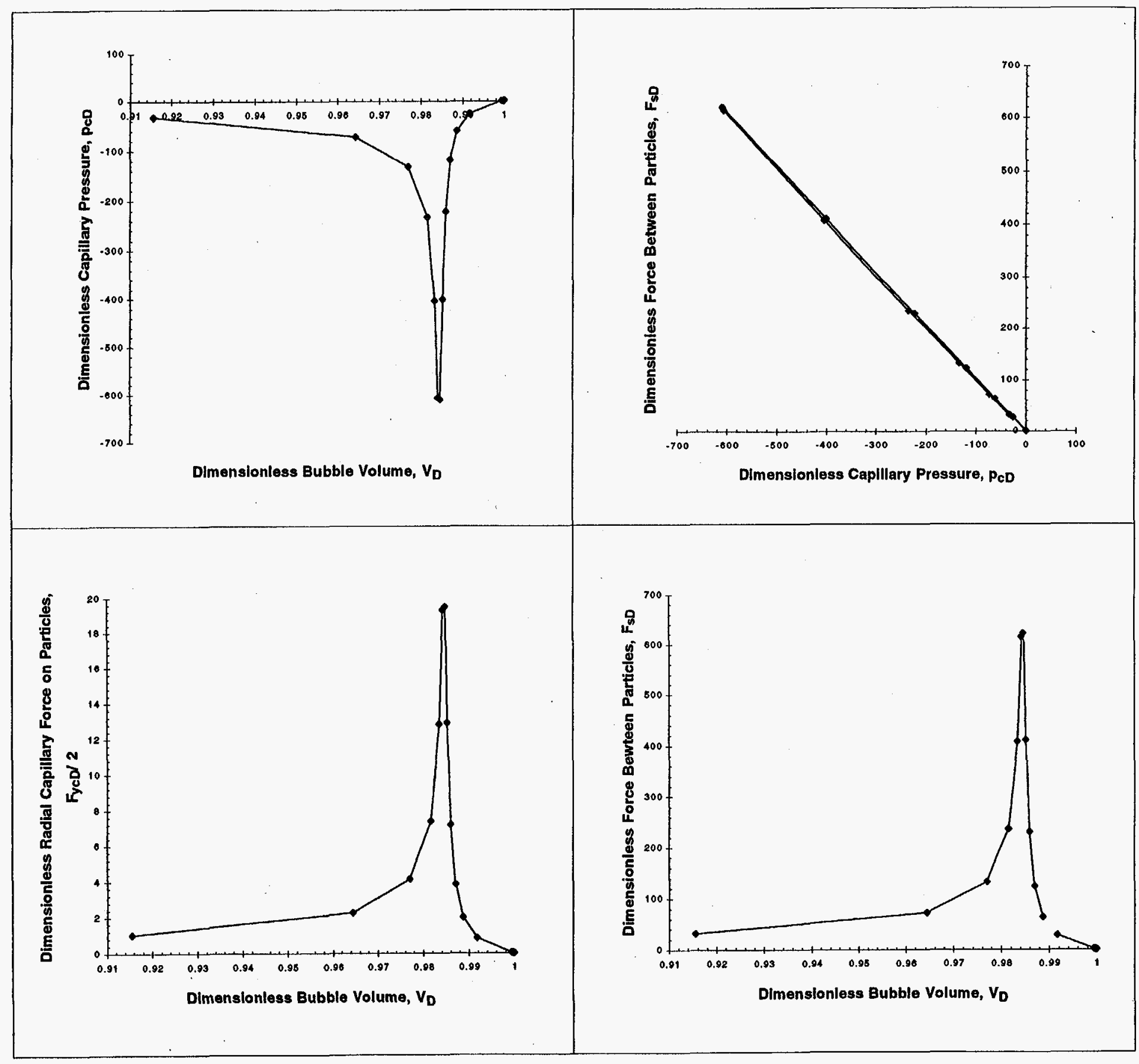

Figure 18. Capillary pressure and stresses on bubble armor as functlons of bubble volume. $n=100 ; \theta=170^{\circ}$ 


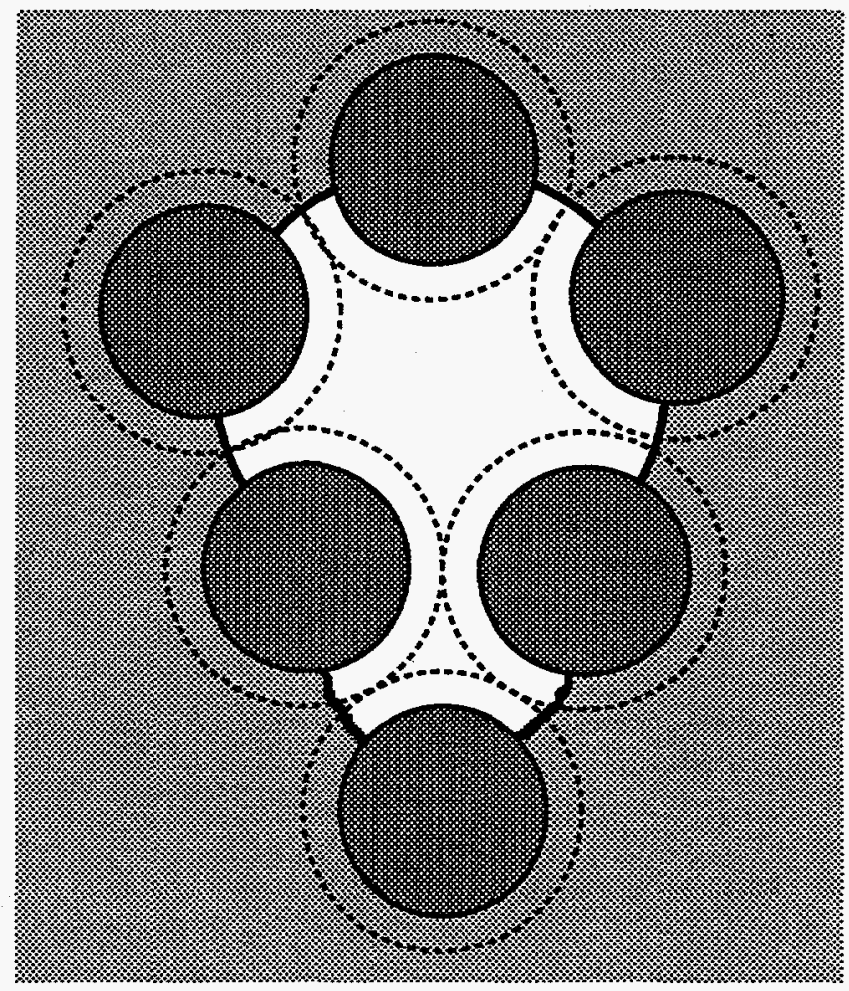

Figure 19. Armored bubble after one solid is expelled from core of armor, but held to armor by liquid-vapor interface (schematic)
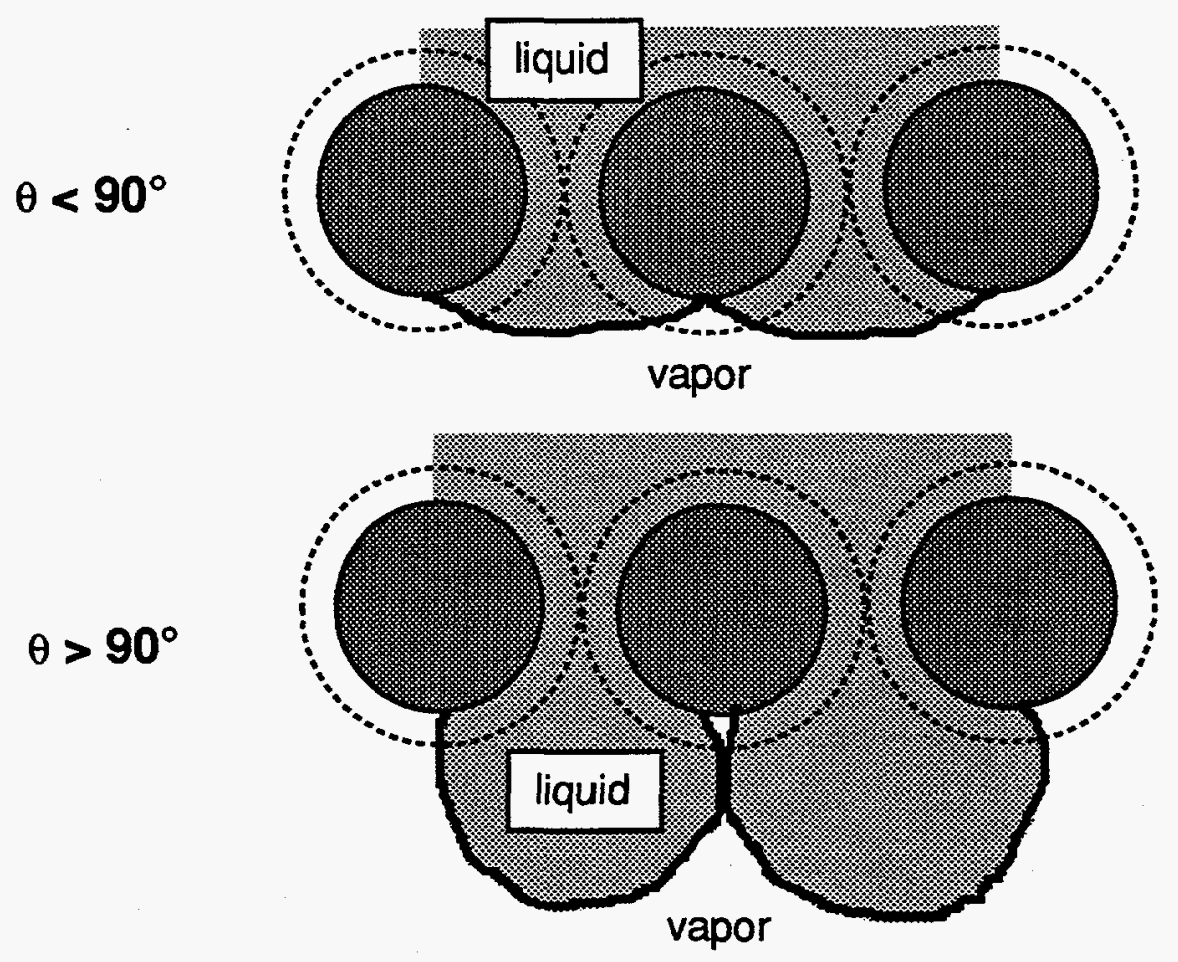

Figure 20. Meeting of liquid-vapor interfaces at minimum bubble volume (schematic) 


\section{Distribution}

No. of

Copies

Offsite

2 Office of Scientific and Technical Information

H. Babad

2540 Cordoba Court

Richland, WA 99352

H. K. Fauske

Fauske and Associates Inc $16 \mathrm{~W} 070 \mathrm{~W} .83$ rd Street

Burr Ridge, IL 60521

C. W. Forsberg

P.O. Box 2008

MS 6495

Oak Ridge, TN 37831

B. C. Hudson

P.O. Box 271

Lindsborg, KA 67456

J. L. Kovach

Nuclear Consulting Services Inc.

P.O. Box 29151

Columbus, $\mathrm{OH}$ 43229-0151

T. S. Kress

102 B Newridge Road

Oak Ridge, TN 37830-8118

T. E. Larson

2711 Walnut Street

Los Alamos, NM 87544
No. of

Copies

4 Los Alamos National Laboratory

P.O. Box 1663

Los Alamos, NM 87545

Attn: D. R. Bennett, K575

W. L. Kubic, K575

K. Pasamehmetlogu, K575

J. R. White, K575

N. G. McDuffie

Civil Engineering Department

Apperson Hall 202

Oregon State University

Corvallis, OR 97331-2302

D. A. Powers

Sandia National Laboratory

7964 Sartan Way NE, MS 0744

Albuquerque, NM 87185-0744

W. Schulz

727 Sweethead Drive

Wilmington, DE 19800

S. E. Slezak

MS 1004

Sandia National Laboratory

P.O. Box 5800

Albuquerque, NM 87110

3 W. R. Rossen

Dept. of Petroleum/Geosystems

Engineering

The University of Texas at Austin

Austin, TX 78712-3246 
No of

Copies

Onsite

6 DOE Richland Operations Office

M. H. Campbell

K. O. Chen

J. M. Gray

C. A. Groendyke

W. F. Hendrickson

G. W. Rosenwald

21 Hanford Contractors

S. A. Barker

W. B. Barton

R. E. Bauer

D. R. Bratzel

R. J. Cash

G. L. Dunford

L. L. Fritts

R. C. Hill

K. M. Hodgson

G. D. Johnson (3)

N. W. Kirch

C. E. Leach

J. W. Lentsch

D. M. Ogden

D. A. Reynolds
S7-73

S7-54

S7-54

S7-54

S7-54

S7-54

R2-11

R2-11

S7-14

S7-14

S7-14

A2-34

T6-06

R1-51

H0-34

S7-14

R2-11

R1-49

S7-14

H0-34

R2-11
No of

Copies

G. R. Sawtelle

A3-37

E. R. Siciliano

H0-31

R. J. Van Vleet

A3-34

L. M. Stock

31 Pacific Northwest National Laboratory

S. Q. Bennett

K7-90

P. R. Bredt

P7-25

M. E. Brewster

K9-62

J. W. Brothers (3)

K9-20

S. A. Bryan

P7-25

J. L. Buelt

P7-41

S. D. Colson

K2-14

P. A. Gauglitz (5)

P7-41

J. H. Konynenbelt

P7-41

T. E. Michener

K7-15

L. G. Morgan

K6-48

B. J. Palmer

K7-15

L. R. Pederson

K2-44

M. R. Powell

P7-19

S. D. Rassat

P7-41

A. Shekarriz

K7-15

C. W. Stewart

K7-15

J. M. Tingey

S. M. Tingey

P7-25

P. D. Whitney.

P7-25

Information Release (5)

K5-12

K1-06 